\title{
Comparative transcriptome analysis uncovers roles of hydrogen sulfide for alleviating cadmium toxicity in Tetrahymena thermophila
}

\author{
Hongrui $L v^{1,2}$, Jing $X u^{1,2}$, Tao Bo ${ }^{2}$ and Wei Wang ${ }^{2^{*}}$ (I)
}

\begin{abstract}
Background: Cadmium (Cd) is a nonessential heavy metal with potentially deleterious effects on different organisms. The organisms have evolved sophisticated defense system to alleviate heavy metal toxicity. Hydrogen sulfide $\left(\mathrm{H}_{2} \mathrm{~S}\right)$ effectively alleviates heavy metal toxicity in plants and reduces oxidative stress in mammals. However, the function of $\mathrm{H}_{2} \mathrm{~S}$ for alleviating heavy metal toxicity in aquatic organisms remains less clear. Tetrahymena thermophila is an important model organism to evaluate toxic contaminants in an aquatic environment. In this study, the molecular roles of exogenously $\mathrm{H}_{2} \mathrm{~S}$ application were explored by RNA sequencing under $\mathrm{Cd}$ stress in $T$. thermophila.
\end{abstract}

Results: The exposure of $30 \mu \mathrm{M} C d$ resulted in T. thermophila growth inhibition, cell nigrescence, and malondialdehyde (MDA) content considerably increase. However, exogenous $\mathrm{NaHS}$ (donor of $\mathrm{H}_{2} \mathrm{~S}, 70 \mu \mathrm{M}$ ) significantly alleviated the $\mathrm{Cd}$-induced toxicity by inhibiting $\mathrm{Cd}$ absorbtion, promoting $\mathrm{CdS}$ nanoparticles formation and improving antioxidant system. Comparative transcriptome analysis showed that the expression levels of 9152 genes changed under Cd stress (4658 upregulated and 4494 downregulated). However, only 1359 genes were differentially expressed with NaHS treatment under Cd stress (1087 upregulated and 272 downregulated). The functional categories of the differentially expressed genes (DEGs) by gene ontology (GO) revealed that the transcripts involved in the oxidation-reduction process, oxidoreductase activity, glutathione peroxidase activity, and cell redox homeostasis were the considerable enrichments between $\mathrm{Cd}$ stress and NaHS treatment under $\mathrm{Cd}$ stress. Kyoto Encyclopedia of Genes and Genomes (KEGG) indicated that the carbon metabolism, glutathione metabolism, metabolism of xenobiotics by cytochrome P450, and ABC transporters were significantly differentially expressed components between $\mathrm{Cd}$ stress and NaHS treatment under $\mathrm{Cd}$ stress in $\mathrm{T}$. thermophila. The relative expression levels of six DEGs were further confirmed through quantitative real-time polymerase chain reaction (qRT-PCR).

Conclusion: NaHS alleviated Cd stress mainly through inhibiting Cd absorbtion, promoting CdS nanoparticles formation, increasing oxidation resistance, and regulation of transport in free-living unicellular T. thermophila. These findings will expand our understanding for $\mathrm{H}_{2} \mathrm{~S}$ functions in the freshwater protozoa.

Keywords: Tetrahymena thermophila, $\mathrm{Cd}$ stress, $\mathrm{H}_{2} \mathrm{~S}$, Transcriptome, Oxidation resistance, Regulation of transport

\footnotetext{
* Correspondence: gene@sxu.edu.cn

${ }^{2}$ Key Laboratory of Chemical Biology and Molecular Engineering of Ministry

of Education, Institute of Biotechnology, Shanxi University, Taiyuan 030006,

China

Full list of author information is available at the end of the article
}

(c) The Author(s). 2021 Open Access This article is licensed under a Creative Commons Attribution 4.0 International License, which permits use, sharing, adaptation, distribution and reproduction in any medium or format, as long as you give appropriate credit to the original author(s) and the source, provide a link to the Creative Commons licence, and indicate if changes were made. The images or other third party material in this article are included in the article's Creative Commons licence, unless indicated otherwise in a credit line to the material. If material is not included in the article's Creative Commons licence and your intended use is not permitted by statutory regulation or exceeds the permitted use, you will need to obtain permission directly from the copyright holder. To view a copy of this licence, visit http://creativecommons.org/licenses/by/4.0/ The Creative Commons Public Domain Dedication waiver (http://creativecommons.org/publicdomain/zero/1.0/) applies to the data made available in this article, unless otherwise stated in a credit line to the data. 


\section{Background}

Heavy metal contamination in aquatic environments has become a global issue [1]. Heavy metals cause adverse effects on the environment because of their toxicity, persistency, and nonbiodegradability [2]. Cadmium (Cd) is one of the most deleterious and serious environmental pollutant to animals and plants [3]. It directly disturbs protein structures and inhibits enzyme activities and causes the formation of reactive oxygen species (ROS), such as superoxide anion $\left(\mathrm{O}_{2}^{-}\right)$, hydroxyl radical $\left(\mathrm{OH}^{*}\right)$, and hydrogen peroxide $\left(\mathrm{H}_{2} \mathrm{O}_{2}\right)$, which in turn induce oxidative stress and membrane damage [4]. ROS leads to serious damages to different macromolecules, such as DNA, RNA, proteins, and lipids [5]. To survive against the stresses, different organisms have evolved a complex of mechanisms involving multiple genes and strategies at physiological, molecular and metabolic levels, such as activating antioxidants, increasing efflux, and overexpressing metal chelators. The organisms effectively respond to ROS through enzymatic and nonenzymatic antioxidant systems [6]. Superoxide dismutase (SOD) is responsible for the conversion of superoxide radicals to $\mathrm{H}_{2} \mathrm{O}_{2}$. Catalase (CAT) decomposes $\mathrm{H}_{2} \mathrm{O}_{2}$ into $\mathrm{H}_{2} \mathrm{O}$ and $\mathrm{O}_{2}$ [7]. Glutathione (GSH) directly or indirectly protects against ROS-mediated cell injury. Several GSHassociated enzymes, such as glutathione reductase, glutathione peroxidase (GPX), and glutathione S-transferase (GST), cumulatively protect against ROS under toxic metal stress [8]. Recent studies revealed that exogenous gaseous signal molecule hydrogen sulfide $\left(\mathrm{H}_{2} \mathrm{~S}\right)$ improve $\mathrm{Cd}$ tolerance in plants by reducing oxidative damage.

$\mathrm{H}_{2} \mathrm{~S}$ is produced endogenously from cysteine mainly by cystathionine $\beta$-synthase (CBS) and cystathionine $\gamma$ lyase (CGL) and is important for various physiological functions in mammals, including synaptic transmission, vascular tone, inflammation, angiogenesis, and protection from oxidative stress [9]. Exogenous $\mathrm{H}_{2} \mathrm{~S}$ acts as a potent antioxidant under $\mathrm{Cd}$ stress by enhancing antioxidant enzymes activities in wheat seedlings [10], and alleviates $\mathrm{Cd}$ toxicity through regulations of $\mathrm{Cd}$ transport across the plasma and vacuolar membranes in Populus euphratica cells [11]. In Brassica rapa, $\mathrm{H}_{2} \mathrm{~S}$ mitigates $\mathrm{Cd}$-induced cell death by inhibiting ROS accumulation [12]. $\mathrm{H}_{2} \mathrm{~S}$ reduced $\mathrm{Cd}$-induced oxidative stress, particularly by enhancing redox status and the activities of ROS and methylglyoxal detoxifying enzymes in rice [13]. However, the functions and signal pathways of $\mathrm{H}_{2} \mathrm{~S}$ under heavy metal stress remain unclear in other organisms.

Ciliates are highly divergent unicellular eukaryotic organisms with nuclear dualism. These unicellular eukaryotic organisms are ubiquitous in various environments [14]. Ciliates play an important role in aquatic ecosystem and are used as whole cell biosensors to evaluate toxicity of various environmental pollutants [15, 16]. Tetrahymena thermophila is a free-living ciliate widely distributed in freshwater environment. It is an excellent model organism for toxicological and ecotoxicological studies in aquatic toxicity test systems. $T$. thermophila contains a large number of gene families that are involved in processes associated with sensing and responding to environmental stresses. The $44 \mathrm{P} 450$ monooxygenase genes and 165 ATP-binding cassette (ABC) transporter genes were identified in T. thermophila $[17,18]$. The 70 putative GST genes exist in the macronuclear genome of $T$. thermophila, which imply that this organism has been exposed to diverse xenobiotics throughout its evolution [19]. T. thermophila has higher sensitivity to heavy metal stress [20]. One of the basic heavy metal resistance mechanisms present in $T$. thermophila is the intracellular sequestration (bio-accumulation), of which the cellular detoxification processes is the chelation of metal cations by endogenous proteins or peptides, such as metallothioneins (MTs), phytochelatins (PCs), and GSH [14]. Heavy metal stress responsive genes and antioxidant defense system allow the survival of Tetmemena in presence of metals in the environment [21]. These heavy metal stress response mechanisms in freshwater ciliates are kinds of self-protection through intracellular regulation.

However, little is known about the mitigative effects on heavy metal stress through exogenous additive in the freshwater protozoa. In this study, we found $\mathrm{H}_{2} \mathrm{~S}$ promoted T. thermophila proliferation and alleviated cellular toxicity induced by $\mathrm{Cd}$. The mechanism of $\mathrm{H}_{2} \mathrm{~S}$ function on T. thermophila stressed under $\mathrm{Cd}$ was evaluated by phenotypic observation, enzyme and metabolites analysis, and high throughput transcriptome sequencing technology. These findings will expand our understanding for $\mathrm{H}_{2} \mathrm{~S}$ functions in aquatic organisms.

\section{Results \\ $\mathrm{H}_{2} \mathrm{~S}$ mitigates inhibition of proliferation of $T$. thermophila under Cd stress}

Heavy metal pollutants caused toxic effects on ciliates, and the effect varied according to the bioavailable concentration and nature of the heavy metal [22]. An assay using the motile response of Tetrahymena pyriformis, gave a sensitivity better than $1 \mu \mathrm{M}$ and a toxicity threshold to $7 \mu \mathrm{M}$ for $\mathrm{Cd}$ [23]. Cd caused a dose-dependent decline in the viability of T. thermophila [24]. To understand the tolerance level of $\mathrm{Cd}$ for $T$. thermophila, the half maximal inhibitory concentration (IC50) value of Cd was determined, and it was calculated to be $30 \mu \mathrm{M}$ for T. thermophila cells at $6 \mathrm{~h}$ culture (Fig. 1a). $\mathrm{H}_{2} \mathrm{~S}$ alleviates $\mathrm{Cd}$ toxicity in plants. Exogenous $\mathrm{H}_{2} \mathrm{~S}$ recovered Cd-induced growth inhibition in Brassica napus, Arabidopsis, and barley [25-27]. $70 \mu \mathrm{M}$ NaHS (donor of $\mathrm{H}_{2} \mathrm{~S}$ ) 

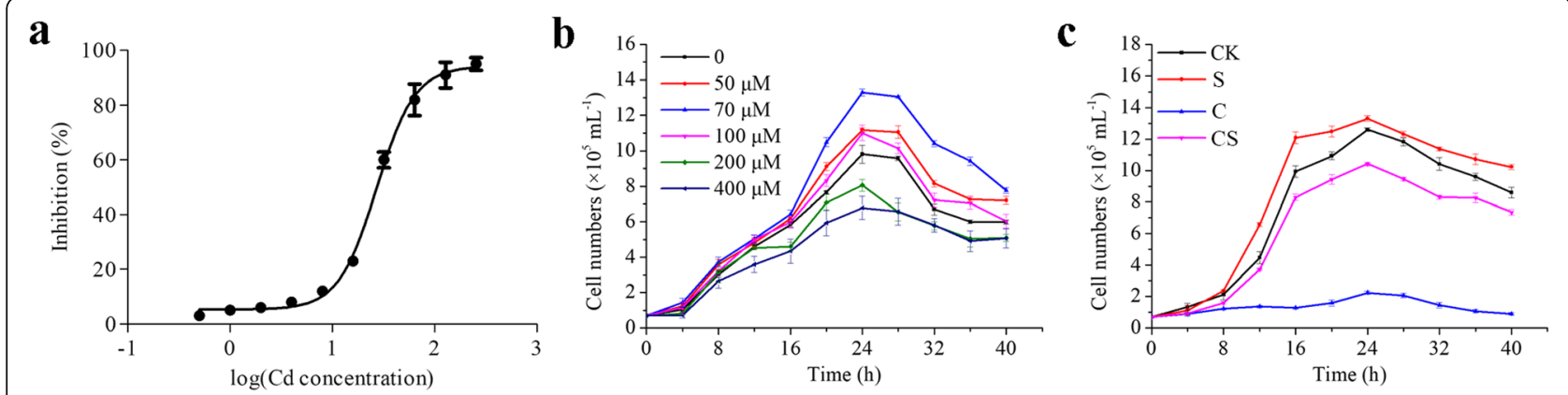

Fig. 1 Proliferation of $\mathrm{T}$. thermophila under $\mathrm{Cd}$ and $\mathrm{H}_{2} \mathrm{~S}$ treatments. a IC50 value of $\mathrm{Cd}$. The inhibition ratio of cell proliferation in different concentrations of $\mathrm{Cd}(0.5,1,2,4,8,16,32,64,128$, and $256 \mu \mathrm{M})$. The IC50 of Cd was calculated by GraphPad Prism 5. b Cell proliferation in different concentrations of $\operatorname{NaHS}(50,70,100,200$, and $400 \mu \mathrm{M})$. c Cell proliferation under $70 \mu \mathrm{M}$ NaHS (S), $30 \mu \mathrm{M} \mathrm{Cd}(\mathrm{C})$, and $30 \mu \mathrm{M} \mathrm{Cd}+70 \mu \mathrm{M}$ NaHS (CS) treatments

largely stimulated proliferation of T. thermophila (Fig. 1b). Furthermore, the proliferation of T. thermophila under $\mathrm{Cd}$ and $\mathrm{NaHS}$ treatments was investigated. An amount of $0.7 \times 10^{5} \mathrm{~mL}^{-1}$ cells was transferred to the SPP medium, and the number of cells was counted every $4 \mathrm{~h}$. The proliferation inhibition of $T$. thermophila under $30 \mu \mathrm{M}$ Cd was dramatically mitigated by $70 \mu \mathrm{M}$ NaHS (Fig. 1c). The results showed exogenous NaHS play a protective role on Cd stress in T. thermophila.

\section{$\mathrm{Cd}$ treatment promotes the production of endogenous $\mathrm{H}_{2} \mathrm{~S}$ and cysteine in $T$. thermophila}

Endogenous $\mathrm{H}_{2} \mathrm{~S}$ is generated through enzymatic pathways in plants. Cysteine desulfhydrases regulate cysteine degradation into pyruvate, ammonia and $\mathrm{H}_{2} \mathrm{~S}$. In contrast, $\mathrm{O}$-acetylserine (thiol) lyase catalyzes the formation of cysteine using $\mathrm{H}_{2} \mathrm{~S}$ and $\mathrm{O}$-acetylserine. These physiological processes are interrelated under $\mathrm{Cd}$ stress [26]. Recently, we also found cysteine is generated by reverse transsulfuration pathway involved CBS and CGL, and de novo pathway involved cysteine synthase (CS) in $T$. thermophila. At the same time, the CBS, CGL, and CS also catalyzed $\mathrm{H}_{2} \mathrm{~S}$ production in vitro [28]. To explore whether endogenous $\mathrm{H}_{2} \mathrm{~S}$ is involved in T. thermophila tolerance to Cd stress, formation of endogenous $\mathrm{H}_{2} \mathrm{~S}$ was investigated under different conditions. 10 to $30 \mu \mathrm{M}$ $\mathrm{Cd}$ increased the $\mathrm{H}_{2} \mathrm{~S}$ content and cysteine levels in a dose-dependent manner. When $T$. thermophila cells were treated with 40 or $50 \mu \mathrm{M} \mathrm{Cd}$, both $\mathrm{H}_{2} \mathrm{~S}$ and cysteine levels decreased due to stronger $\mathrm{Cd}$ toxicity (Fig. 2a, b). Exogenous cysteine treatment enhanced $\mathrm{H}_{2} \mathrm{~S}$ level and maintained $\mathrm{H}_{2} \mathrm{~S}$ at high level under $\mathrm{Cd}$ stress (Fig. 2c).

\section{$\mathrm{H}_{2} \mathrm{~S}$ alleviates lipid peroxidation and improves antioxidant capacity under $\mathrm{Cd}$ stress}

$\mathrm{Cd}$ significantly inhibits the growth of microorganisms and plants. The treatment using $30 \mu \mathrm{M} \mathrm{Cd}$ also led to the stunted growth and nigrescence of $T$. thermophila after being exposed for $24 \mathrm{~h}$. However, the toxic symptoms were drastically alleviated with NaHS supplement. The exogenous NaHS significantly inhibited $\mathrm{Cd}$

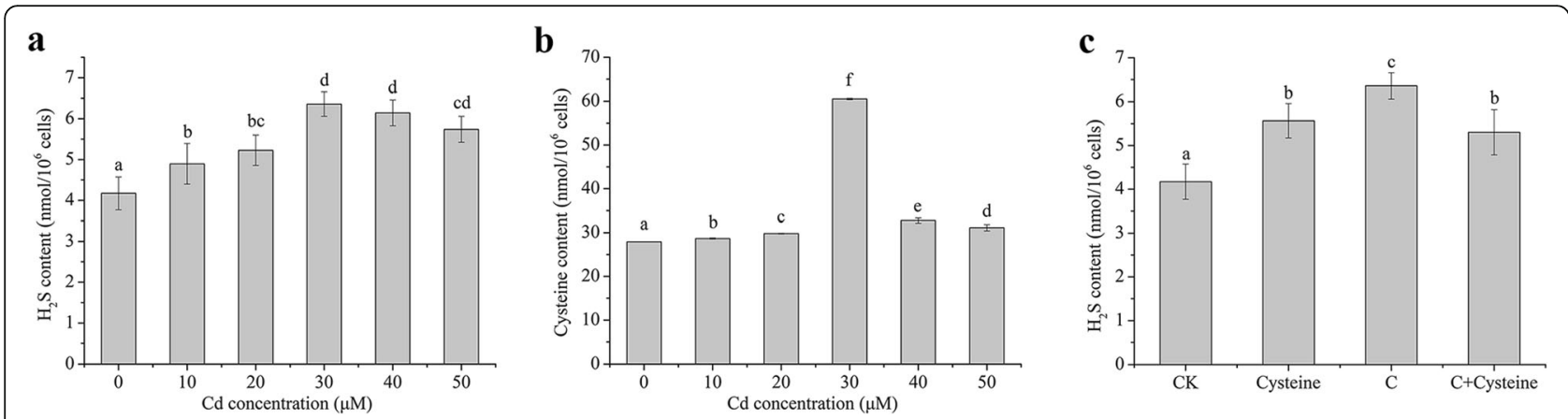

Fig. 2 Analysis of endogenous $\mathrm{H}_{2} \mathrm{~S}$ and cysteine contents in $T$ thermophila. a Changes of $\mathrm{H}_{2} \mathrm{~S}$ content in various $\mathrm{Cd}$ concentrations. b Changes of cysteine content in various $\mathrm{Cd}$ concentrations. c The effects of cysteine on $\mathrm{H}_{2} \mathrm{~S}$ content under $\mathrm{Cd}$ stress. Cells were treated with $1 \mathrm{mM}$ cysteine, $30 \mu \mathrm{M} \mathrm{Cd}(\mathrm{C})$, and $30 \mu \mathrm{M} \mathrm{Cd}+1 \mathrm{mM}$ cysteine (C+Cysteine) for $6 \mathrm{~h}$. Data are means \pm SE of three biological repeats, error bars indicate error standard. Means denoted by the same letter were not significantly different at $P>0.05$, and different letters indicate statistically significantly differences $(P<0.05)$ by Duncan Multiple Range Test (DMRT) 
accumulation (decrease by 26\%) in the T. thermophila cells (Fig. 3a). The $\mathrm{H}_{2} \mathrm{~S}$-mediated $\mathrm{Cd}$ accumulation was significantly decreased with hypotaurine $\left(\mathrm{HT}\right.$, a $\mathrm{H}_{2} \mathrm{~S}$ scavenger that reverses the effect of $\mathrm{H}_{2} \mathrm{~S}$ ) treatment. $\mathrm{NaHS}$ application increased $\mathrm{H}_{2} \mathrm{~S}$ level by $38 \%$ but did not affect it in $\mathrm{H}_{2} \mathrm{~S}+\mathrm{HT}$ group compared to untreated control (Fig. 3b). The results implied the regulatory role of $\mathrm{H}_{2} \mathrm{~S}$ in $\mathrm{Cd}$ accumulation in T. thermophila.

$\mathrm{Cd}$ stress caused lipid peroxidation and induced malondialdehyde (MDA) production of T. thermophila cells in a dose-dependent manner. Low concentrations of $\mathrm{Cd}$ had less effect on the MDA content in T. thermophila cells. However, 30 and $50 \mu \mathrm{M} \mathrm{Cd}$ lead to the MDA content of the cells increased by 91 and 395\%, respectively (Fig. S1). In comparison, the MDA content of the cells had no significant changes when the cells were treated with NaHS. However, the NaHS treatment markedly decreased the MDA content of T. thermophila cells under Cd stress (Fig. 3c).

It is well known that antioxidant defense system increases organism tolerance against metal-induced toxicity by upregulating the nonenzymatic antioxidants and different antioxidant enzymes. $\mathrm{H}_{2} \mathrm{~S}$ increase GSH content and antioxidant enzymes activity in Arabidopsis [26]. Under Cd stress, GSH content increased by $51 \%$ and exogenous NaHS supplement further increased the
GSH content in T. thermophila (Fig. 3d). But, the increase of GSH was reversed with HT supply. Furthermore, SOD activity increased by $92 \%$ and CAT activity increased by $29 \%$ under Cd stress. $\mathrm{H}_{2} \mathrm{~S}$ supplement also enhanced SOD and CAT activities in T. thermophila cells (Fig. 3e, f). Combined application of NaHS and HT decreased the activities of SOD and CAT. The results indicated that $\mathrm{H}_{2} \mathrm{~S}$ could alleviate $\mathrm{Cd}$ toxicity by improving the antioxidant capacity of $T$. thermophila cells.

$\mathrm{NaHS}$ increased the insoluble $\mathrm{Cd}$ fractions in salix leaves and roots [29]. Schizosaccharomyces pombe directly scavenge the free $\mathrm{Cd}^{2+}$ ions and the detoxification process occurs through the production of $\mathrm{CdS}$ nanoparticles [30]. In T. thermophila, spherical CdS nanoparticles in yellow colour with an average particle diameter of $186.9 \pm 60.8 \mathrm{~nm}$ were observed under $\mathrm{Cd}$ treatment, and the nanoparticles amount increased by adding NaHS (Fig. 4). However, UVvisible spectrum analysis showed that no $\mathrm{CdS}$ formation was found in vitro (Fig. S2). The formation of Ag nanoparticles from Ag ions was one of the defense mechanisms of $T$. thermophila against the toxic silver ions. Compared to $\mathrm{AgNO}_{3}, \mathrm{Ag}$ nanoparticles were remarkably less toxic. The Ag nanoparticles stored intracellularly in the food vacuoles of $T$. thermophila [31]. The results showed that the formation
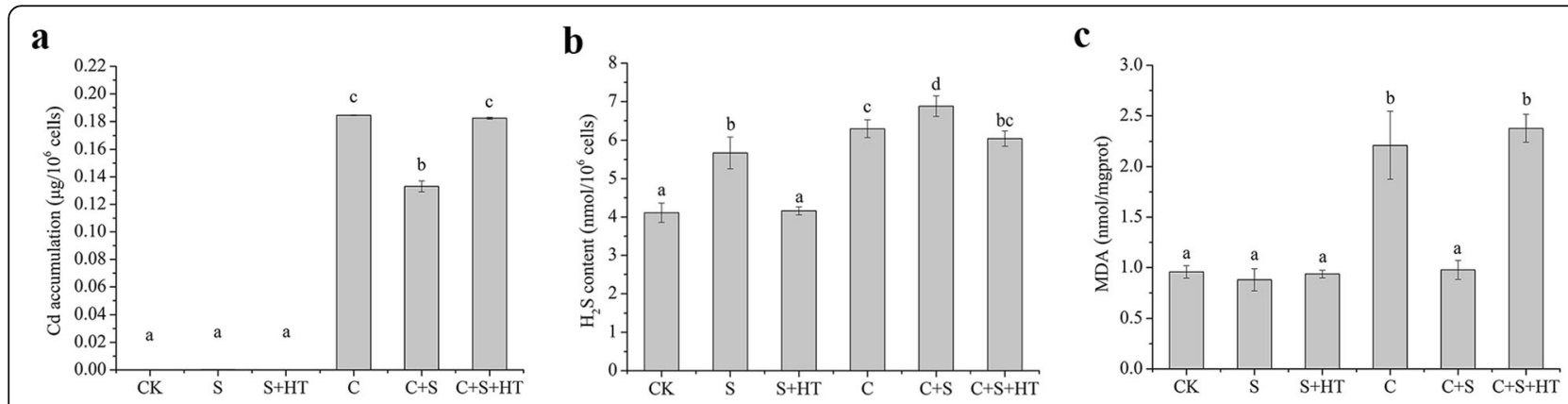

d
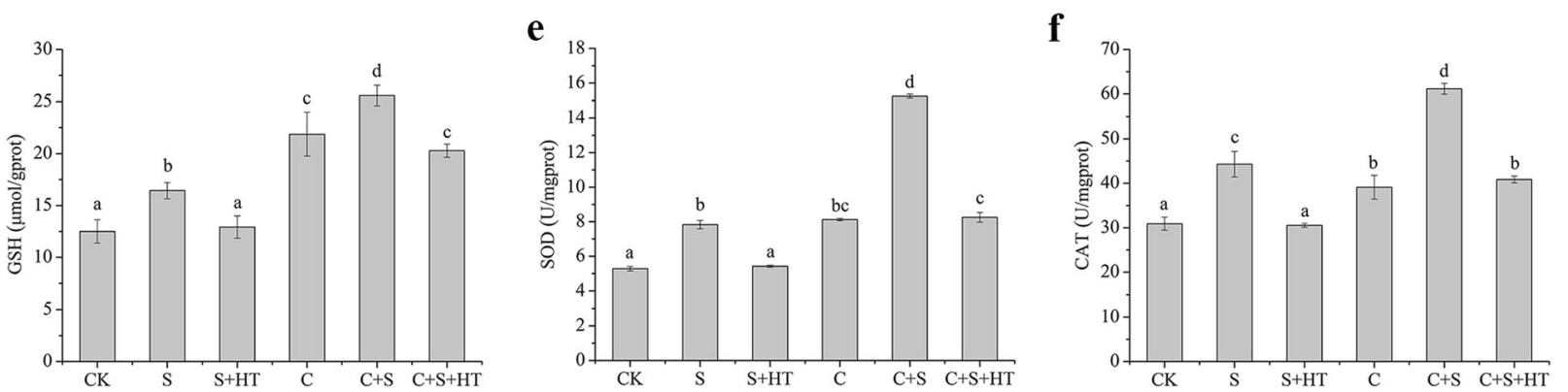

Fig. 3 Effects of $\mathrm{NaHS}$ on $\mathrm{Cd}$ accumulation, $\mathrm{H}_{2} \mathrm{~S}$ content, lipid peroxidation, and antioxidant system under $\mathrm{Cd}$ stress. a Cd accumulation under different conditions in T. thermophila. $\mathbf{b} \mathrm{H}_{2} \mathrm{~S}$ contents in $\mathrm{T}$. thermophila cells when the cells were treated by various conditions. $\mathbf{c}$ Effects of Cd and $\mathrm{H}_{2} \mathrm{~S}$ on lipid peroxidation. $\mathbf{d}$-f Cells in the logarithmic phase were grown in the medium with different treatments, and GSH content (d), SOD activity (e), and CAT activity (f) were measured. CK, S, S+HT, C, C+S, and C+S+HT correspond to the groups of cells exposed to nutrients only, at $70 \mu \mathrm{M} \mathrm{NaHS}, 70 \mu \mathrm{M}$ NaHS$+140 \mu \mathrm{M} \mathrm{HT}, 30 \mu \mathrm{M} \mathrm{CdCl}, 30 \mu \mathrm{M} \mathrm{CdCl} 2+70 \mu \mathrm{M} \mathrm{NaHS}$, and $30 \mu \mathrm{M} \mathrm{CdCl} 2+70 \mu \mathrm{M} \mathrm{NaHS}+140 \mu \mathrm{M}$ HT respectively. Data are means \pm SE of three biological repeats, error bars indicate error standard. Means denoted by the same letter were not significantly different at $P>0.05$, and different letters indicate statistically significantly differences $(P<0.05)$ by Duncan Multiple Range Test (DMRT) 
a

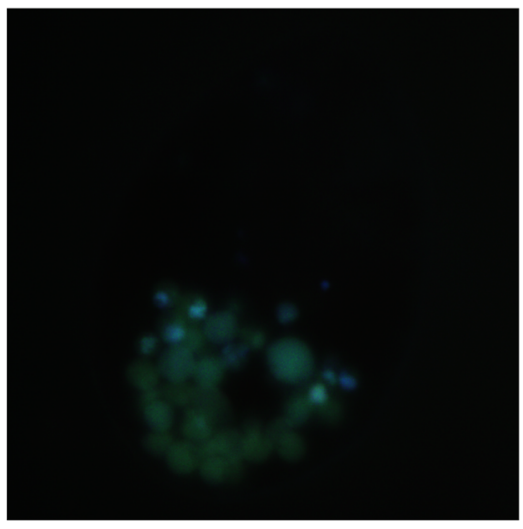

c

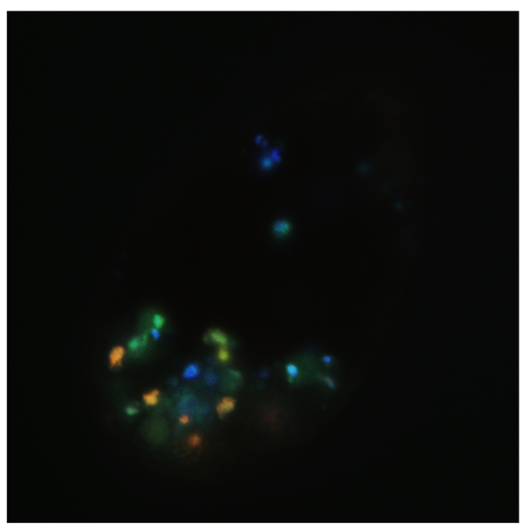

e

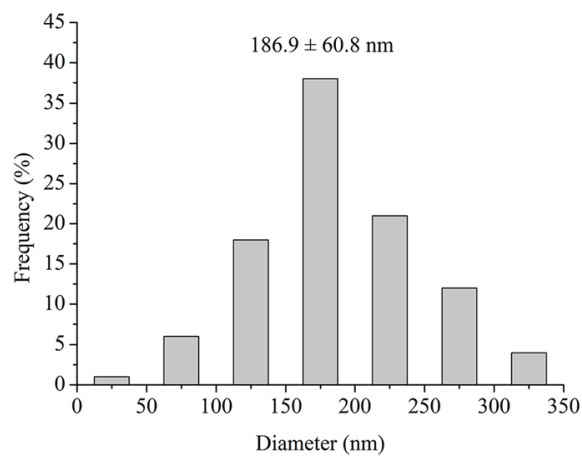

b

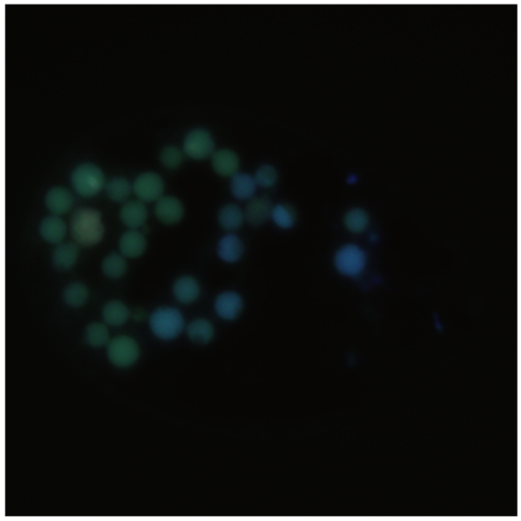

d

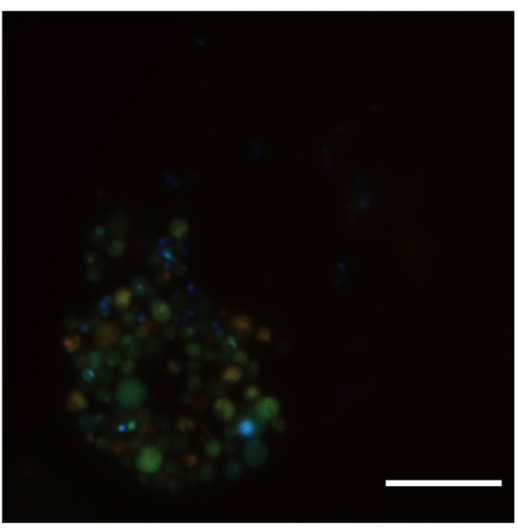

f

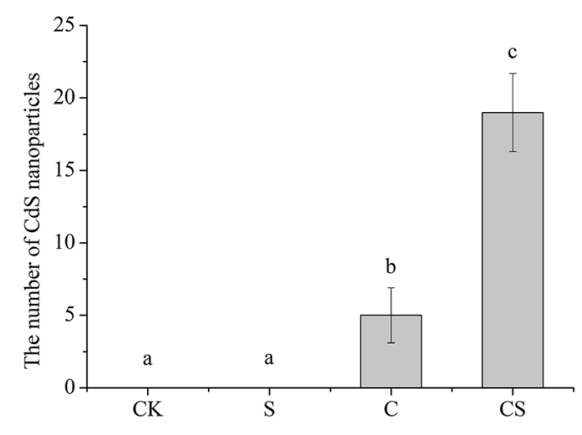

Fig. 4 Images of live T. thermophila cells under ultraviolet excitation light. Cells were exposed to nutrients only (a), $70 \mu \mathrm{M} \mathrm{NaHS} \mathrm{(b),} 30 \mu \mathrm{M} C \mathrm{Cd}(\mathbf{c})$, and $30 \mu \mathrm{M} \mathrm{Cd}+70 \mu \mathrm{M}$ NaHS (d). Scale bar $=10 \mu \mathrm{m}$. e histogram of particle size distribution obtained from corresponding images. $\mathbf{f}$ The number of CdS nanoparticles with different treatments $(n=25)$

of $\mathrm{CdS}$ nanoparticles decrease $\mathrm{Cd}$ bioavailability and toxicity in $T$. thermophila.

\section{Characterization of the sequenced Illumina libraries}

Tetrahymena evolved various efficient detoxification pathways allowing the survival from heavy metal stress, such as overexpressing metal chelators and activating antioxidant signal pathways. The oxidative stress related mechanism of Ag nanoparticles was revealed at the transcriptional level. Some oxidative stress related genes were upregulated upon exposure to sub-lethal concentrations of Ag compounds, although intracellular ROS levels and SOD and CAT activities were not elevated in Tetrahymena [32]. To further explore the mechanisms of $\mathrm{H}_{2} \mathrm{~S}$ alleviating $\mathrm{Cd}$ stress in T. thermophila, RNA-seq was employed to investigate the changes in genomewide gene expression for four groups of cells: exposed to nutrients only (CK), with $70 \mu \mathrm{M}$ NaHS (S), under $30 \mu \mathrm{M}$ 
$\mathrm{CdCl}_{2}$ (C), and $70 \mu \mathrm{M}$ NaHS+ $30 \mu \mathrm{M} \mathrm{CdCl}$ (CS), with three biological replicates. A total of 305.2 million pairend reads with Q20 > 97\% and Q30 > 93\% were obtained from 12 libraries (Table 1). Among the short clean reads, more than $94 \%$ were mapped to the $T$. thermophila Functional Genomics Database (http://tfgd.ihb.ac.cn/). Approximately 95\% of the reads from each library were perfectly matched to the reference genes, and more than $93 \%$ of the reads in the libraries were mapped to single locations. Half of these uniquely mapped reads in each library were mapped to the sense strand, whereas the other half was mapped to the antisense strand (Table S1). Then, the mapped reads were further classified and annotated using TopHat [33]. The correlations between the three replicated samples were calculated on the basis of the normalized expression results (Fig. S3). The correlation coefficient between the three replicated samples was reasonable for the $\mathrm{CK}, \mathrm{S}$, and CS groups, but that between $\mathrm{C} 1$ and $\mathrm{C} 2$ or between $\mathrm{C} 1$ and $\mathrm{C} 3$ was lower than $70 \%$. Thus, the $\mathrm{C} 1$ sample was abnegated.

\section{Differentially expressed genes (DEGs) in response to NaHS treatment, Cd stress, and NaHS treatment under $\mathrm{Cd}$ stress}

DEGs were hierarchically clustered to obtain a comprehensive view of the differential gene expression under NaHS treatment, Cd stress, and NaHS treatment with $\mathrm{Cd}$ stress (Fig. 5a). Under NaHS treatment, the expression level of 191 genes changed. Among them, 134 genes were upregulated and 57 genes were downregulated. Under Cd stress, the expression level of 9152 genes significantly changed, including 4658 upregulated genes and 4494 downregulated genes. A total of 1087 genes were upregulated and 272 genes were downregulated with $\mathrm{NaHS}$ treatment under $\mathrm{Cd}$ stress. The expression levels of most genes recovered under $\mathrm{Cd}$ stress with $\mathrm{NaHS}$ treatment. A total of 4122 genes were upregulated and 3738 genes were downregulated between Cd stress and NaHS treatment under Cd stress (Fig. 5b).

The 95 DEGs overlapped between CK vs. S (50.0\%) and $\mathrm{C}$ vs. CS $(1.2 \%)$, indicating that $\mathrm{H}_{2} \mathrm{~S}$-responsive transcripts under normal condition were far fewer than those under Cd stress. The 806 DEGs in CK vs. C (8.8\%) were common to CK vs. CS (59.3\%), and the 6001 genes overlapped between CK vs. C (65.6\%) and C vs. CS (76.3\%) (Fig. 5c), suggesting most of the Cd-responsive transcripts were altered by $\mathrm{H}_{2} \mathrm{~S}$. The absolute value of the $\log 2$ ratio ranged from 1.00 to 14.70 in $\mathrm{CK}$ vs. C, and ranged from 1.00 to 12.21 in C vs. CS (Fig. 5d). The significantly upregulated genes under $\mathrm{Cd}$ stress $(\log 2 \mathrm{FC}$ $>8$ ) were considerably related to oxidoreductase, GPXs, GSTs, heat shock protein, and MTs (Table S2). By systematic bioinformatics approach, the predicted $T$. thermophila $\mathrm{Cd}$ proteome included thioredoxins, heat shock proteins, GPXs, GSTs, and MT protein [34]. Compared with $\mathrm{Cd}$ stress, the unigenes significantly downregulated in the NaHS treatment under $\mathrm{Cd}$ stress $(\log 2 \mathrm{FC}<-8)$ were mainly related to oxidoreductase, GPXs, GSTs, and heat shock protein (Table S3). The results indicated that the redox system is sensitive for NaHS treatment and Cd stress in T. thermophila.

\section{Gene ontology (GO) enrichment analysis of DEGs}

To obtain the functional annotations of the DEGs for $\mathrm{Cd}$ stress and $\mathrm{H}_{2} \mathrm{~S}$ treatment under $\mathrm{Cd}$ stress, GO category enrichment analysis was performed. For the comparison of CK vs. C, the 5740 DEGs were classified as 50 functional groups (Fig. S4). The functional groups were divided into three categories: biological process, molecular function, and cellular component. The biological process mainly comprises DEGs involved in metabolic process $(2619,45.63 \%)$, cellular process $(2589,45.10 \%)$, single-organism process $(1406,24.49 \%)$, biological regulation $(777,13.5 \%)$, and localization $(706,12.30 \%)$. In the

Table 1 Summary statistics of transcriptome sequencing

\begin{tabular}{llllll}
\hline Sample name & Pair-end reads & Base sum & Q20 (\%) & Q30 (\%) & GC content (\%) \\
\hline CK1 & $24,039,989$ & $7.18 \mathrm{G}$ & 97.62 & 93.23 & 34.4 \\
CK2 & $26,249,793$ & $7.85 \mathrm{G}$ & 97.45 & 92.89 & 35.38 \\
CK3 & $27,398,030$ & $8.18 \mathrm{G}$ & 97.76 & 93.58 & 36.48 \\
S1 & $24,065,268$ & $7.20 \mathrm{G}$ & 97.78 & 93.65 & 36.46 \\
S2 & $25,128,738$ & $7.51 \mathrm{G}$ & 97.67 & 93.36 & 34.23 \\
S3 & $27,739,667$ & $8.26 \mathrm{G}$ & 97.77 & 93.57 & 34.89 \\
C1 & $7.36 \mathrm{G}$ & 97.68 & 93.35 & 33.98 \\
C2 & $7.42 \mathrm{G}$ & 97.64 & 93.2 & 33.22 \\
C3 & $24,782,234$ & 97.68 & 93.32 & 33.39 \\
CS1 & $7.39 \mathrm{G}$ & 97.72 & 93.44 & 34.4 \\
CS2 & $24,731,403$ & $6.86 \mathrm{G}$ & 97.75 & 93.55 & 35.38 \\
CS3 & $22,918,319$ & 97.7 & 93.39 & 36.48 \\
\hline
\end{tabular}


a

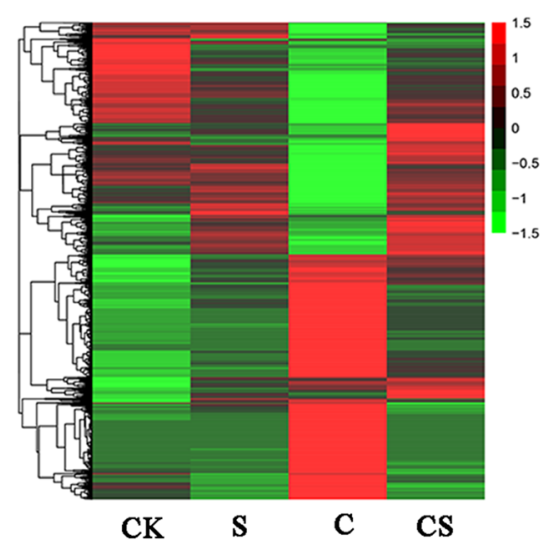

c

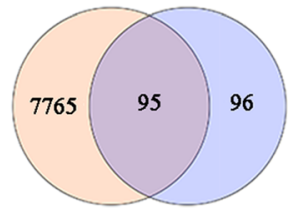

C vs. CS CK vs. S

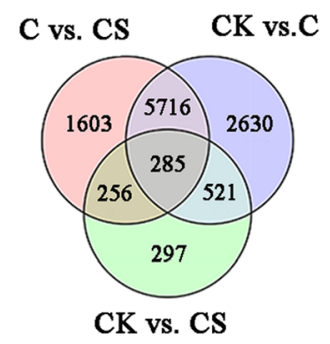

$\mathbf{b}$

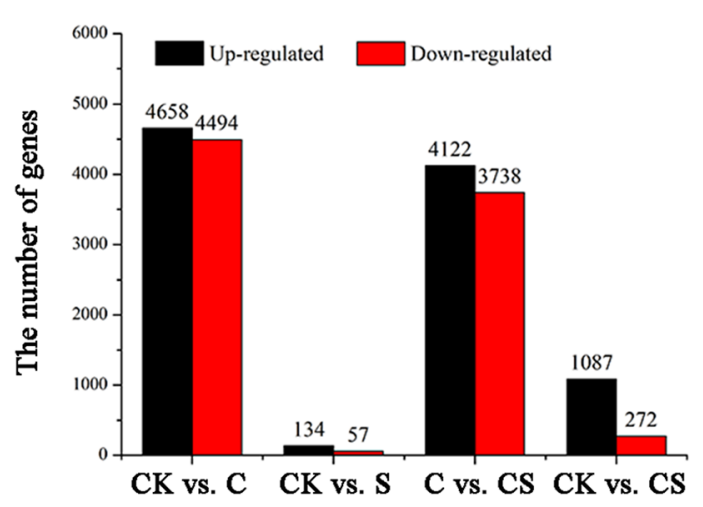

d
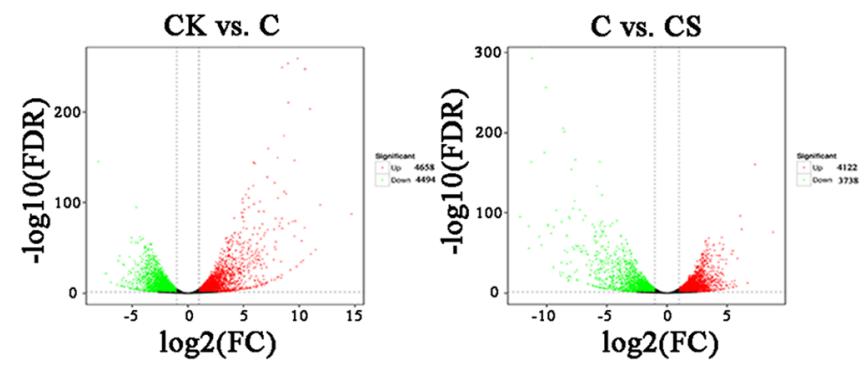

Fig. 5 Responses of DEGs to $\mathrm{H}_{2} \mathrm{~S}$ treatment, $\mathrm{Cd}$ stress, and $\mathrm{H}_{2} \mathrm{~S}$ treatment under $\mathrm{Cd}$ stress. a Hierarchical clustering of all DEGs based on log 10 fragments per kilobase million (FPKM) values. The color from green to red represents the gene expression level from low to high. $\mathbf{b}$ Distribution of upregulated and downregulated transcripts in each comparison. c Venn diagram analysis of differentially expressed transcripts between four pairwise comparisons. ) Volcano plots of DEGs between samples. The threshold $q<0.05$ was used to determine the significance of DEGs. Red and green dots represent up- and down-regulated genes, respectively, and black dots indicate transcripts that did not change significantly in the CK vs. C or C vs. CS

category of cellular components, membrane (2711, $47.23 \%)$, membrane part (2517, 43.85\%), cell (1798, $31.32 \%)$, cell part $(1784,31.08 \%)$, and organelle (1094, 19.06\%) were the most represented groups. Among the molecular function category, the major groups were catalytic activity (3081, 53.68\%), binding (2160, 37.63\%), and transporter activity (416, 7.25\%). For the comparison of $\mathrm{C}$ vs. CS, the 4883 DEGs were also classified as 50 functional groups. Between $\mathrm{C}$ vs. CS and CK vs. C, they had exactly identical classification patterns (Fig. S4).

Next, TopGO enrichment analysis was performed to obtain a detailed classification through false discovery rate (FDR) adjusted $P$-value of $<0.05$ as the cutoff (Fig. 6). The distribution of enriched GO terms indicated that several DEGs were involved in oxidation-reduction process (GO: 0055114), oxidoreductase activity (GO:0016491) and glutathione peroxidase activity (GO:0004602) in both CK vs. C and C vs. CS. Under Cd stress, 283 DEGs were included in oxidoreductase activity and 231 DEGs participated in oxidation-reduction process. Compared with $\mathrm{Cd}$ stress, 263 DEGs constituted the oxidoreductase activity with NaHS addition, and 182 DEGs involved in oxidation-reduction process. Furthermore, response to oxidative stress (GO:0006979) was enriched in CK vs. C. Cell redox homeostasis (GO:0045454) was enriched in C vs. $\mathrm{CS}$. These data indicated that $\mathrm{H}_{2} \mathrm{~S}$ responds to $\mathrm{Cd}$ stress mainly through the adjustment of the redox balance.

\section{Kyoto encyclopedia of genes and genomes (KEGG) metabolic pathway enrichment analysis}

The annotated T. thermophila transcripts were mapped to the KEGG pathways to investigate the genes involved in important metabolic pathways. Under Cd stress, the 1116 DEGs were mapped to the 252 KEGG pathways. For $\mathrm{NaHS}$ treatment under $\mathrm{Cd}$ stress compared with $\mathrm{Cd}$ stress, 966 DEGs were mapped to 247 KEGG pathways. The pathways considerably related to carbon metabolism, GSH metabolism, drug metabolism-cytochrome P450, and metabolism of xenobiotics by cytochrome $\mathrm{P} 450$ (Fig. 7a, b). Under Cd stress, 54 DEGs (4.84\%) were distributed in the carbon metabolism, and 48 DEGs (4.97\%) also enriched in this pathway with adding NaHS. The KEGG pathway of GSH metabolism includes primarily GPX and GST. 52 DEGs (4.66\%) were enriched at the GSH metabolism under Cd stress, and 54 DEGs (5.59\%) were also enriched with adding NaHS. Under Cd stress, 39 DEGs (3.49\%) or 40 DEGs (3.58\%) were distributed in drug metabolism-cytochrome $\mathrm{P} 450$ or metabolism of 
a

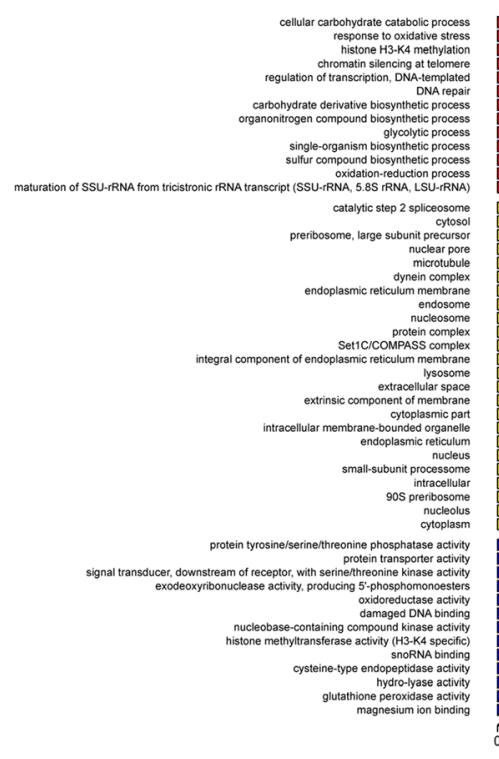

b

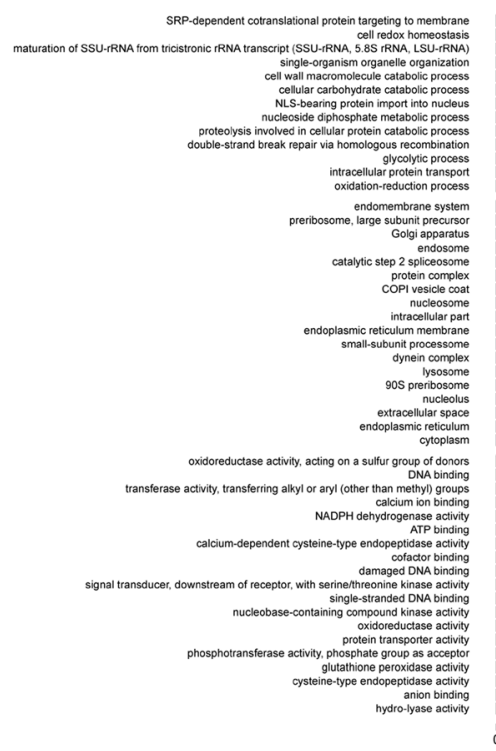

CK vs. C

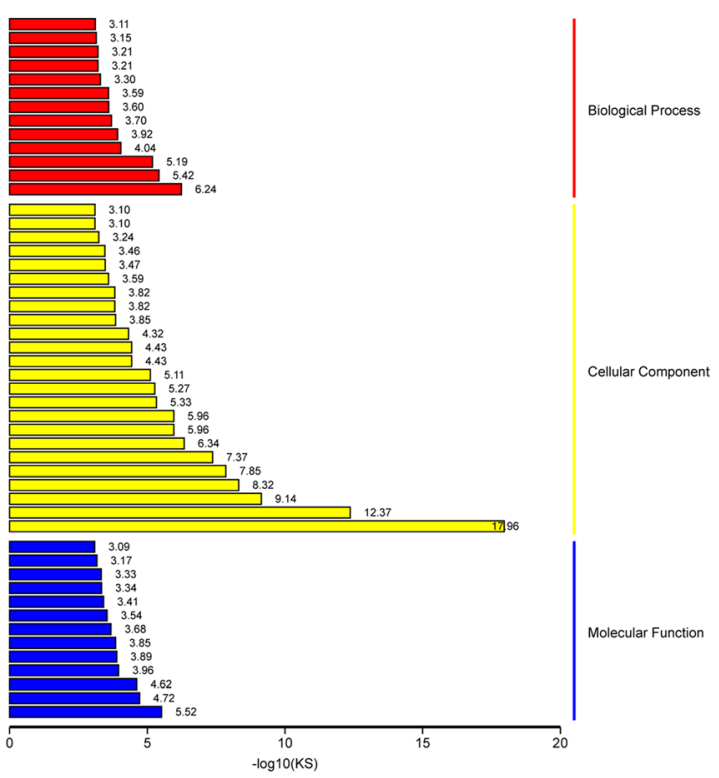

C vs. CS

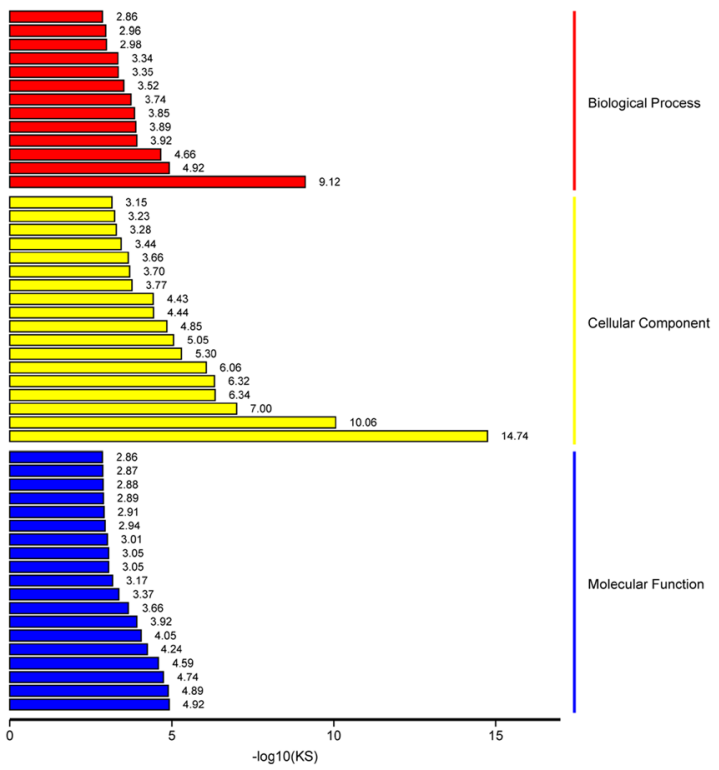

Fig. 6 TopGO enrichment analysis of DEGs. a TopGO enrichment analysis for GO in CK vs. C. b TopGO enrichment analysis for GO in C vs. CS. The ordinate coordinates represent three $\mathrm{GO}$ categories under the $\mathrm{GO}$ term level, including the annotation of the term and the abscissa is the enriched degree. The low KS result indicates more significant enrichment

xenobiotics by cytochrome P450, and 40 DEGs (4.14\%) or 42 DEGs $(4.35 \%)$ were enriched in the two pathways with NaHS addition, respectively. Besides, under Cd stress, 67 DEGs (6.00\%) were distributed in ABC transporters (Fig. S5), and 70 DEGs (7.25\%) were enriched in this pathway with adding NaHS. The considerably enriched pathways in $\mathrm{C}$ vs. CS were similar to those of $\mathrm{CK}$ vs. $\mathrm{C}$, indicating the important detox effects through $\mathrm{H}_{2} \mathrm{~S}$ under Cd stress.
Regulation of cytochrome P450 and GSH metabolism under $\mathrm{Cd}$ stress and with NaHS treatment

Cytochrome $\mathrm{P} 450$ represents an important participant in regulatory networks of organism responses to $\mathrm{Cd}$ stress. The expression of genes encoding cytochrome $\mathrm{P} 450$ family proteins was strongly induced by $\mathrm{Cd}$ in rice [35]. In the wolf spider Pardosa pseudoannulata, cytochrome $\mathrm{P} 450$ genes were found to respond to $\mathrm{Cd}$ stress [36]. A 


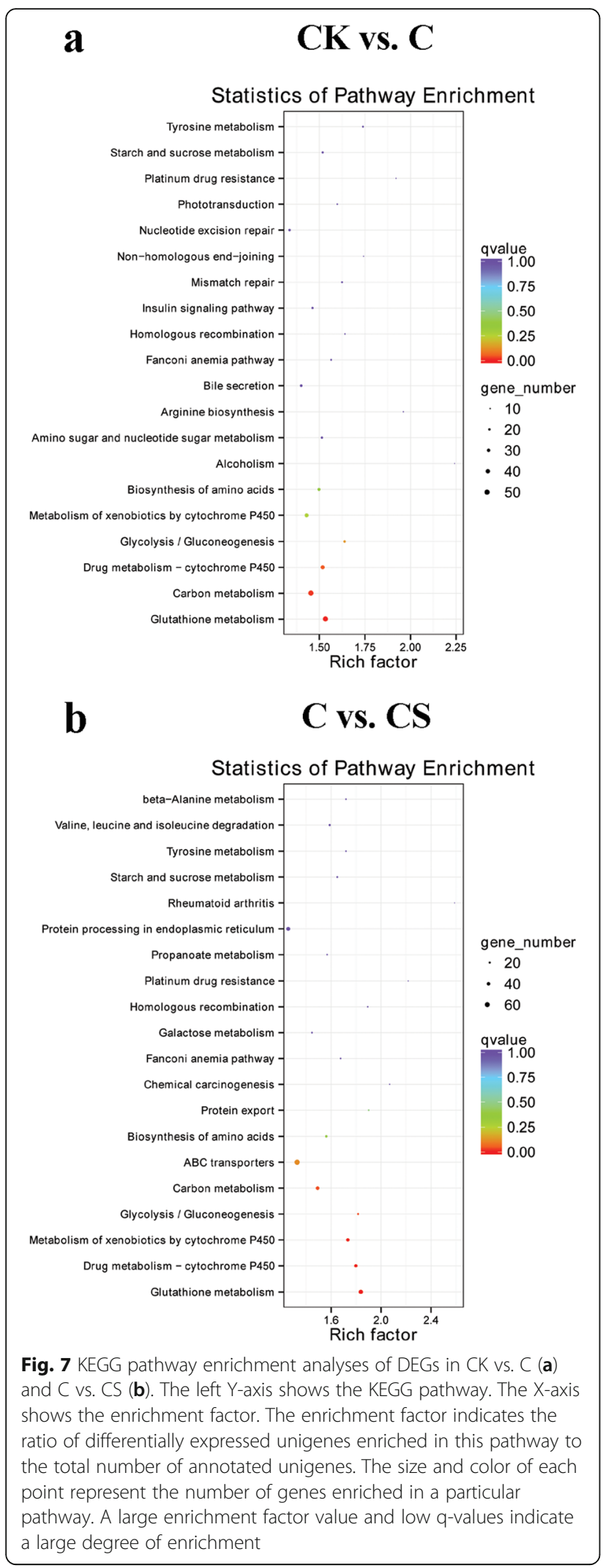

total of 44 putative functional cytochrome $\mathrm{P} 450$ genes were identified and classified into 13 families and 21 sub-families according to standard nomenclature in $T$. thermophila. Cd induced the expression of 6 cytochrome P450 genes and inhibited the expression of 9 cytochrome $\mathrm{P} 450$ genes $(|\log 2 \mathrm{FC}|>1)$. NaHS addition reversed the expression of 11 of them (Table 2). Under $\mathrm{Cd}$ stress, metabolism of xenobiotics by cytochrome P450 was significantly enriched by KEGG pathway analysis on DEGs, of which 32 DEGs were markedly upregulated (Fig. S6), including oxidoreductase, aldehyde dehydrogenase, 30 GSTs, and 29 of them were markedly downregulated when $\mathrm{NaHS}$ was added.

Sixty-three cytosolic GSTs have been identified in $T$. thermophila. Under Cd stress, GSH metabolism was significantly enriched by KEGG pathway analysis on upregulated genes (Fig. S7). The upregulated DEGs included 31 GSTs and 8 GPXs. Compared with Cd stress, GSH metabolism was also significantly enriched on downregulated genes with NaHS addition, including 30 GSTs and 8 GPXs. Specifically, the 8 upregulated GPXs and 29 GSTs induced by $\mathrm{Cd}$ stress returned to normal level with adding NaHS. GSTs detoxify xenobiotic compounds by linking the -SH group of antioxidant GSH covalently to a substrate [37]. Given the role of GSH in the detoxification of heavy metals, regulation of GSH, GPXs, and GSTs by $\mathrm{H}_{2} \mathrm{~S}$ play an important role in ameliorating Cd stress.

Table 2 Cytochrome P450 genes response to $\mathrm{Cd}$ or $\mathrm{H}_{2} \mathrm{~S}$ in $\mathrm{CK}$ vs. C and/or C vs. CS

\begin{tabular}{llll}
\hline Gene ID & Gene name & CK vs. C Log2FC & C vs. CS Log2FC \\
\hline TTHERM_00191380 & CYP5004A1 & -1.222948644 & 0.726722049 \\
TTHERM_00198210 & CYP5005A2 & -2.013242365 & 1.999422405 \\
TTHERM_00198230 & CYP5005A4 & -1.097798649 & 0.315367456 \\
TTHERM_00201580 & CYP5005A9 & 3.180647522 & -3.21680049 \\
TTHERM_00201630 & CYP5005A10 & 2.330671223 & -1.440492726 \\
TTHERM_00898330 & CYP5005A15 & 2.830883564 & -2.410899716 \\
TTHERM_01122770 & CYP5005A18 & -1.082132664 & 0.922173282 \\
TTHERM_01122780 & CYP5005A19 & -1.307720517 & 1.50630203 \\
TTHERM_00185610 & CYP5006A1 & -2.139546793 & 1.632428135 \\
TTHERM_00283410 & CYP5007B1 & 1.820581108 & -1.11407977 \\
TTHERM_00444460 & CYP5009A1 & 2.445007531 & -1.43647057 \\
TTHERM_00723150 & CYP5010A1 & -1.023465363 & 0.416122088 \\
TTHERM_00527100 & CYP5011A1 & -1.608260175 & 2.51348553 \\
TTHERM_00241770 & CYP5013C2 & -2.841933829 & 2.710002866 \\
TTHERM_00313500 & CYP5013E1 & 1.277727898 & -1.197335044 \\
\hline
\end{tabular}


Regulation of $A B C$ transporters under $C d$ stress and with NaHS treatment

GSH marked xenobiotic molecules are excreted from cells via phase III proteins such as $A B C$ transporter enzymes. Based on the KEGG pathway analysis, the ABC transporters related to detoxification of $\mathrm{Cd}$ in $T$. thermophila was screened and listed in Fig. S8. Under $\mathrm{Cd}$ stress, 49 DEGs involved in the enrichment of $A B C$ transporters were markedly upregulated, while 18 DEGs were downregulated. The $\mathrm{ABC}$ transporter family of $T$. thermophila was classified into 8 distinct groups [18]. The ABCA subfamily comprises of a total of $32 \mathrm{mem}$ bers, which included 9 upregulated genes and 3 downregulated genes under $\mathrm{Cd}$ stress. The $\mathrm{ABCB}$ subfamily consists of 26 transporters, of which 5 genes were upregulated and 5 genes were downregulated. The ABCC subfamily comprises 60 transporters and represents the largest family of $\mathrm{ABC}$ transporters in T. thermophila. Twenty-two genes were induced by $\mathrm{Cd}$ and 6 genes were downregulated. The ABCG subfamily includes 39 transporters, and 9 genes were upregulated under $\mathrm{Cd}$ stress and 3 genes were inhibited. ABCG19 (TTHERM_ 00034920) was induced up to 357 folds under Cd stress (Table S2), which suggested it could play an important role in detoxifying $\mathrm{Cd}$ toxicity. $\mathrm{H}_{2} \mathrm{~S}$ has been demonstrated for direct regulating $\mathrm{ABC}$ transporters to induce stomatal movement in plants. Exogenous $\mathrm{H}_{2} \mathrm{~S}$ induces stomatal closure and this effect is impaired by the $A B C$ transporter inhibitor glibenclamide in guard cells [38]. Compared with Cd stress, 42 DEGs were downregulated and 28 DEGs were upregulated for $\mathrm{ABC}$ transporters with NaHS addition. Most of the expression of $A B C$ transporters under $\mathrm{Cd}$ stress was restored and some of them even hyper activated by exogenous NaHS addition, which is in relation to $\mathrm{H}_{2} \mathrm{~S}$ lowering the cellular concentration of $\mathrm{Cd}$ (Fig. 3a) and promoting $\mathrm{CdS}$ nanoparticles formation (Fig. 4).

\section{Quantitative real-time polymerase chain reaction (qRT- $P C R$ ) validation of differentially expressed transcripts}

To validate the accuracy and reliability of transcriptome sequencing, six DEGs involved in chelating heavy metals, redox reaction, and stress response were evaluated through qRT-PCR. NaHS slightly affected the expression of the genes under non-stressed condition. Under $\mathrm{Cd}$ stress, the expression levels of the genes were significantly upregulated. The $\log 2 \mathrm{FC}$ of the CdMT genes were ranked as $M T T 5 \approx M T T 3>M T T 1$ under Cd stress (Table S2). The expression levels of four genes decreased with NaHS addition, including SSA6, OXR1, GLR2, and MTT3. On the contrary, the expression level of MTT1 further increased and MTT5 had no obvious change with NaHS treatment under Cd stress (Fig. 8). The three CdMT isoform genes present differential expression patterns between $\mathrm{Cd}$ stress and NaHS treatment under $\mathrm{Cd}$ stress, indicating their functional diversification. The correlation between qRT-PCR and RNA-seq was measured by scatter plotting log2-fold changes, which showed a positive correlation coefficient in both techniques (Pearson coefficient $R^{2}=0.95$ ), thereby indicating the reliability of the sequencing data.

\section{Discussion}

NaHS treatment improved Cd tolerance in $T$. thermophila $\mathrm{Cd}$ is a nonessential and highly toxic metal that adversely affects the growth and development of different living organisms. 50-150 $\mu \mathrm{M} \mathrm{Cd}$ inhibited the elongation of Arabidopsis roots in a dose-dependent manner [26]. Survival rate of three ciliates decreased remarkably with increasing $\mathrm{Cd}$ exposure, and the LC50 for Notohymena $(5 \mu \mathrm{g} / \mathrm{mL})$ was higher than Tetmemena $(2 \mu \mathrm{g} / \mathrm{mL})$ and Euplotes $(2 \mu \mathrm{g} / \mathrm{mL})$ [39]. The LC50 of Cd for T. thermophila SB1969 strain was $44.5 \mu \mathrm{M}$ for $24 \mathrm{~h}$ exposure [40]. In the present study, IC50 of Cd for T. thermophila was $30 \mu \mathrm{M}$ for $6 \mathrm{~h}$ treatment. Several strategies have been developed to alleviate the toxicity of $\mathrm{Cd}$. Among them, $\mathrm{H}_{2} \mathrm{~S}$ participates in suppressing Cd stress. $100 \mu \mathrm{M} \mathrm{H} \mathrm{H}_{2} \mathrm{~S}$ supplementation exhibited an inhibitory effect on $\mathrm{Cd}$ uptake and accumulation in rice [13]. $300 \mu \mathrm{M} \mathrm{H}_{2} \mathrm{~S}$ alleviates $\mathrm{Cd}$ toxicity by changing $\mathrm{Cd}$ chemical forms and increasing the activities of antioxidant enzymes in salix [29]. We found that $70 \mu \mathrm{M}$ NaHS promoted the proliferation of $T$. thermophila and alleviated Cd toxicity by inhibiting the accumulation of $\mathrm{Cd}$ in cells (Fig. 1, 3a). Furthermore, we also found that copper $(\mathrm{Cu})$ inhibited the proliferation of $T$. thermophila, and NaHS alleviated its inhibitory effect (Fig. S9).

\section{$\mathrm{H}_{2} \mathrm{~S}$ participates in oxidative damage scavenging systems in $T$. thermophila}

The antioxidant systems of enzymatic and nonenzymatic antioxidants could immediately abolish ROS. $\mathrm{H}_{2} \mathrm{~S}$ alleviates oxidative damage against copper stress in wheat, and toxic effects of lead on cotton antioxidant activity [41, 42]. In ROS scavenging pathways, $\mathrm{O}_{2}^{-}$is converted to $\mathrm{H}_{2} \mathrm{O}_{2}$ by SOD, and $\mathrm{H}_{2} \mathrm{O}_{2}$ is subsequently reduced to $\mathrm{H}_{2} \mathrm{O}$ and $\mathrm{O}_{2}$ by CAT. $30 \mu \mathrm{M} \mathrm{Cd}$ induced a sharp generation of MDA and enhanced activity of SOD and CAT in T. thermophila (Fig. 3). The SOD and CAT enhance the basal antioxidant capacity to overcome oxidative stress caused by $\mathrm{Cd}$ [43]. GSH acts as substrate for GPX to catalyze $\mathrm{H}_{2} \mathrm{O}_{2}$ [39]. The GSH content was notable upregulated under $\mathrm{Cd}$ stress, and with the addition of NaHS, the GSH content further increased (Fig. 3). The improvement of GSH levels and increase of SOD and CAT activities under NaHS treatment promoted detoxification of ROS, and protected the cells from oxidative damage. In addition, the accumulation of MDA content 


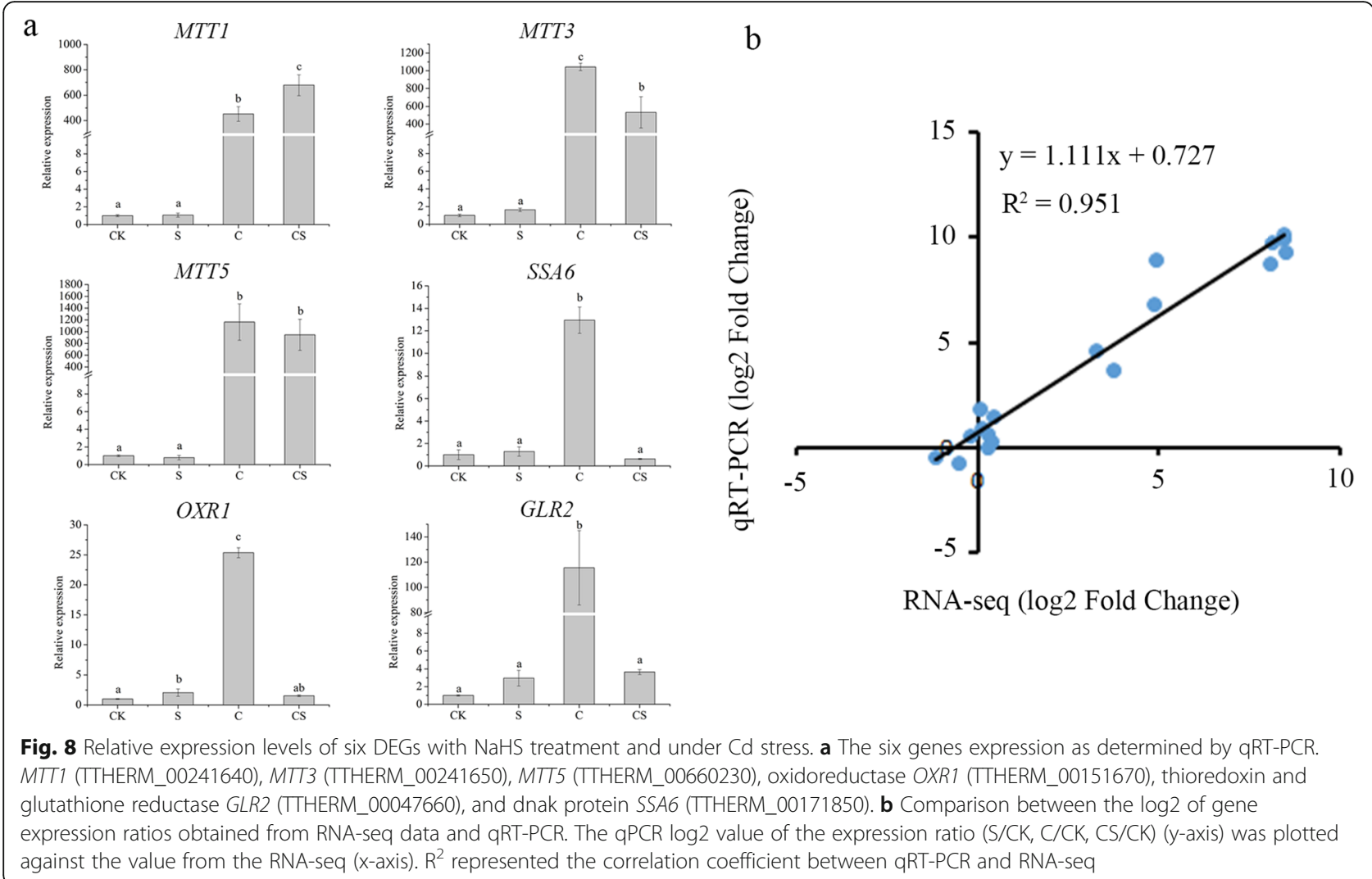

significantly reduced by the exogenous NaHS treatment. The exogenous NaHS promotes endogenous $\mathrm{H}_{2} \mathrm{~S}$ formation and indirectly balances the $\mathrm{O}_{2}{ }^{-}$and $\mathrm{H}_{2} \mathrm{O}_{2}$ levels and maintains redox balance in T. thermophila.

$\mathrm{Cd}$ stress leads to the significant molecular and physiological changes in different organisms. The whole transcriptional reprogramming is regarded as a vital molecular response to $\mathrm{Cd}$ stress. Enzymes responsible for detoxification and antioxidant process can alleviate oxidative stress. GPX protects organisms from oxidative damage by catalyzing the reaction between ROS and GSH [44]. Under arsenate stress, glutathione peroxidase family protein was over-expressed in T. pyriformis, which is involved in protecting the cells from oxidative damage [45]. Oxidoreductases participate in the oxidation-reduction process, and $\mathrm{Cd}$ exposure led to the remarkable variations of these genes in crayfish hepatopancreas [46]. Under Cd stress, 27 oxidoreductases and 9 glutathione peroxidase family proteins were upregulated in the oxidation-reduction process enrichment term in T. thermophila through GO analysis. Among them, the expression levels of 25 oxidoreductases and the all 9 glutathione peroxidase family proteins returned to normal upon the NaHS addition. The redox system was disrupted after $\mathrm{Cd}$ exposure and recovered through NaHS supplement in $T$. thermophila.
MTs are sulfhydryl-rich proteins, which have been known as multifunctional proteins and as pivotal members of the cellular integrated stress response system. $T$. thermophila has three CdMTs (MTT1, MTT3, and MTT5) and two CuMTs (MTT2 and MTT4). MTT5 is the strongest induced, while MTT3 is the least induced by $\mathrm{Cd}$ stress at $1 \mathrm{~h}$ or $24 \mathrm{~h}[40,47]$. However, the ranking of relative expression values can change relying on the duration of heavy metal treatment [14]. We found that the ranking of induction fold change values was MTT5 $\approx M T T 3>M T T 1$ when $T$. thermophila was stressed by Cd stress at $6 \mathrm{~h}$ (Fig. 8, and Table S2). Comparisons of qRT-PCR values obtained by different researchers are not similar due to differences in the experimental conditions. MTs also display oxyradical scavenging capacity and specifically neutralize hydroxyl radicals [48]. Interestingly, the upregulated expression of MTT1 under Cd stress further increased with NaHS treatment. On the contrary, the upregulated expression of MTT3 under Cd stress decreased with NaHS treatment. Meanwhile, the upregulated expression of MTT5 under Cd stress has no significant change with NaHS treatment. These data further indicated that different MT genes have conserved and various function and regulated by different molecular mechanism.

To protect the cell from oxidative stress, heat shock proteins (HSPs) are greatly induced. In response to $\mathrm{Cd}$ 
exposure for $24 \mathrm{~h}$ in Tetmemena, there was around 46fold increase in the hsp70 transcriptional expression as compared to control [21]. In the present study, three HSPs (TTHERM_000351139, TTHERM_00351140, TTHERM_00171850) were found to activate by Cd and the expression level returns to normal by NaHS addition (Fig. 8, and Table S2). It seems that $\mathrm{H}_{2} \mathrm{~S}$ involved in the detoxification of $\mathrm{Cd}$ through the antioxidative stress signal pathway.

\section{$\mathrm{H}_{2} \mathrm{~S}$ alleviates $\mathrm{Cd}$ stress by regulating cytochrome $\mathrm{P} 450$, GST and ABC transporters}

The metabolism of xenobiotics comprises of three phases, including modification (phase I), conjugation (phase II), and excretion (phase III). Toxicity responsive genes of $T$. thermophila has been partially revealed, including cytochrome P450 gene family in phase I, GST gene family in phase II, and the $\mathrm{ABC}$ transporter superfamily in phase III [19]. Cytochrome P450 is in charge of the metabolism of most xenobiotics and efficiently eliminates foreign chemicals [36]. Cytochrome P450 was induced at $6 \mathrm{~h}$ of $\mathrm{Cd}$ treatment, then decreased to control levels after 18-24 h, and expressed at low level after $48 \mathrm{~h}$ of $\mathrm{Cd}$ exposure in Physcia adscendens [49]. We found that $\mathrm{Cd}$ altered the expression of 15 cytochrome P450 genes, and NaHS reversed the expression of most of these genes in T. thermophila.

P450 enzymes and GSTs are a well-conserved mechanism of the $\mathrm{Cd}$ response in a wide range of organisms [35]. GSTs are a large protein family with a wellestablished role in the conjugation of xenobiotics with GSH [50]. GSH forms complexes with heavy metals and serves as the first line of defense against heavy metals stress [51]. GST plays important roles through GSH metabolism in the protection against oxidative damage resulting from the high levels of ROS under Cd stress in Chironomus riparius [52]. In Euplotes crassus, copper and zinc significantly increased the expression of GST [53]. In animals, $\mathrm{Cd}$ is a redox-inactive metal that binds to the thiol group of GSH [54]. The expression level of 31 GSTs was upregulated under Cd stress. Among them, the expression level of 29 GSTs was downregulated with NaHS addition in T. thermophila.

GSH marked xenobiotic molecules are transported via phase III proteins such as $A B C$ transporters. The $A B C$ transporters comprise large protein families that mediate various physiological processes [55]. In fission yeast, $\mathrm{Cd}$ forms complexes with either GSH or PCs and subsequently transports into vacuoles via the $\mathrm{ABC}$ transporters. The $\mathrm{ABC}$ transporters in plants transport $\mathrm{GS}_{2}-$ $\mathrm{Cd}$ or $\mathrm{PC}-\mathrm{Cd}$ complexes into subcellular compartments or out of cells [56]. MRP1 is a well-known ABCC family gene in human, and also regarded as GS-X pumps [57]. Moreover, MRP5, another $\mathrm{ABC}$ transporter $\mathrm{C}$ family gene, has an important role in the detoxification of $\mathrm{Cd}$ [58]. MRP proteins are potential mediators of heavy metal resistance in zebrafish cells [59]. ABCC52 is a MRP-like gene in $T$. thermophila and induced by $\mathrm{Cd}$ and recovered through NaHS treatment. In T. thermophila, the membrane pump protein encoded by ABCT gene abcb15 enhance the tolerance of DDT and protect cells from this exogenous toxin by efficiently pumping the toxin to the extracellular space [60]. The $A B C B 15$ of T. thermophila shares a $32.3 \%$ amino acid identity with $A B C B 1$ in human, which has been shown to confer resistance to or transport a wide variety of toxic compounds [18]. The induction of $A B C B 1$ was detected in Euglena exposed to $\mathrm{Cd}$ [61]. Exposure to $\mathrm{Cd}$ in the gills and hepatopancreas of oyster showed activation of $A B C B 1$ protein but no significant changes to its mRNA, suggesting post-transcriptional regulation of $A B C B 1$ [62]. We do not detect the change of $A B C B 15$ at transcriptional level under Cd stress in T. thermophila, and the post-transcriptional regulation needs further study. As a whole, a total of 67 DEGs were enriched in the $A B C$ transporter pathway under $C d$ stress, and the $A B C$ transporter pathway was significantly altered with $\mathrm{NaHS}$ addition. So, the decrease of $\mathrm{Cd}$ accumulation and toxicity under NaHS treatment partially attribute to regulation of $\mathrm{CdS}$ nanoparticles transport by $\mathrm{ABC}$ transporter pathway in T. thermophila cells.

\section{Conclusion}

$\mathrm{H}_{2} \mathrm{~S}$ physiologically alleviated growth inhibition under $\mathrm{Cd}$ stress and accumulation of $\mathrm{Cd}$ in $\mathrm{T}$. thermophila. $\mathrm{H}_{2} \mathrm{~S}$ promoted formation of CdS nanoparticles and decreased $\mathrm{Cd}$ bioavailability and toxicity, which mitigated lipid peroxidation and improved GSH levels as well as SOD and CAT activities for detoxification of ROS. $\mathrm{H}_{2} \mathrm{~S}$ affected various metabolic processes and molecular functions under $\mathrm{Cd}$ stress, including glutathione metabolism, metabolism of xenobiotics by cytochrome P450, GPXs, Cytochrome P450s, GSTs, and ABC transporters. Taken together, $\mathrm{H}_{2} \mathrm{~S}$ protects $T$. thermophila from $\mathrm{Cd}$ stress by inhibiting $\mathrm{Cd}$ absorbtion, promoting $\mathrm{CdS}$ nanoparticles formation, increasing oxidation resistance, and regulation of transport.

\section{Methods}

\section{Strains and culture conditions}

T. thermophila B2086 was obtained from the Tetrahymena Stock Center (http://tetrahymena.vet.cornell.edu/, Cornell University, Ithaca). The cells were cultured in a $1 \times \mathrm{SPP}$ medium $(\mathrm{pH} 7.4)$ containing $1 \%$ proteose peptone, $0.1 \%$ glucose, $0.2 \%$ yeast extract, and $33.3 \mu \mathrm{M}$ EDTA- $\mathrm{FeNa}_{2}$ at $30^{\circ} \mathrm{C}$ with continuous shaking [63]. For physiological and biochemical analyses, cells were 
transferred to $10 \mathrm{~mL}$ of SPP medium with the same initial concentration at $0.7 \times 10^{5} \mathrm{~mL}^{-1}$.

\section{Cellular proliferation analysis}

Various $\mathrm{Cd}$ concentrations ranging from $0.5 \mu \mathrm{M}$ to $256 \mu \mathrm{M}$ were used to determine the IC50 of Cd for $T$. thermophila cells for $6 \mathrm{~h}$ treatment. The S-curve was plotted with GraphPad Prism 5 in terms of inhibition rates and Cd concentrations. In a pilot study, 6 levels of $\mathrm{NaHS}$ (donor of $\mathrm{H}_{2} \mathrm{~S}$ ) concentrations $(0,50,70,100$, 200, $400 \mu \mathrm{M})$ were explored for treating T. thermophila cells. Based on the results of the pilot study, $70 \mu \mathrm{M}$ NaHS was identified as the optimum positive effect $\mathrm{H}_{2} \mathrm{~S}$ concentration, which was subsequently used as the processing condition in the subsequent experiment (Fig. 1b). To analyze the effects on cell proliferation of $\mathrm{H}_{2} \mathrm{~S}$ under Cd stress, cells were uniformly grown in the SPP medium with $30 \mu \mathrm{M} \mathrm{Cd}$ (IC50) in the presence or absence of $70 \mu \mathrm{M}$ NaHS (optimum positive effect concentration), and their starting concentration was $0.7 \times 10^{5}$ $\mathrm{mL}^{-1}$. Each treatment was replicated 3 times, and the sample was taken every $4 \mathrm{~h}$. The number of cells was determined using a blood cell counting chamber. The formation of CdS by NaHS and $\mathrm{CdCl}_{2}$ in vitro was negligible at present low $\mathrm{Cd}$ and $\mathrm{H}_{2} \mathrm{~S}$ concentrations [29].

\section{Measurement of $\mathrm{H}_{2} \mathrm{~S}$ and cysteine contents}

The cells were collected by centrifugation, and lysates were prepared by sonication. The crude extracts were centrifuged at $12,000 \mathrm{~g}$ for $10 \mathrm{~min}$ at $4{ }^{\circ} \mathrm{C}$, and $\mathrm{H}_{2} \mathrm{~S}$ quantification was performed according the instruction in the $\mathrm{H}_{2} \mathrm{~S}$ assay kit (Nanjing Jiancheng Bioengineering Institute, China). Cysteine content was determined as described previously [64].

\section{Measurement of $\mathrm{Cd}$ concentration}

T. thermophila cells were cultured with $30 \mu \mathrm{M} \mathrm{Cd}$ alone or with the addition of $70 \mu \mathrm{M} \mathrm{NaHS}$ treatments for $24 \mathrm{~h}$. After centrifugation, the cells that accumulated $\mathrm{Cd}$ were removed from the medium. The $\mathrm{Cd}$ in the medium was measured using inductively coupled plasma atomic emission spectroscopy (ICP-OES, iCAP 7000 Series, Thermo Scientific). The results represented the average of three independent experiments.

\section{Assay of MDA, GSH, SOD, and CAT}

The cells $\left(3 \times 10^{6}\right)$ were exposed to various $\mathrm{Cd}$ concentrations for $6 \mathrm{~h}$ or $70 \mu \mathrm{M}$ NaHS before they were collected and ultrasonically lysed. The lysate was centrifuged at $12,000 \mathrm{~g}$ for $20 \mathrm{~min}$ at $4{ }^{\circ} \mathrm{C}$. The protein quantitation was evaluated through the bicinchoninic acid (BCA) assay. The amount of lipid peroxidation product MDA was determined by the thiobarbituric acid
(TBA) method according to the reaction of MDA with TBA [65]. Each experiment was done in triplicate.

The cells in the logarithmic phase were divided into four groups with different treatments: (1) CK, without chemical treatments (the standard SPP solution); (2) S, treatment with NaHS $(70 \mu \mathrm{M})$; (3) S+HT, treatment with NaHS $(70 \mu \mathrm{M})$ and HT $(140 \mu \mathrm{M})$; (4) C, treatment with $\mathrm{Cd}(30 \mu \mathrm{M})$; and (5) $\mathrm{C}+\mathrm{S}$, treatment with $\mathrm{Cd}(30 \mu \mathrm{M})$ and $\mathrm{NaHS}(70 \mu \mathrm{M}) ;(6) \mathrm{C}+\mathrm{S}+\mathrm{HT}$, treatment with $\mathrm{Cd}$ $(30 \mu \mathrm{M})$, NaHS $(70 \mu \mathrm{M})$, and HT $(140 \mu \mathrm{M})$. After treatment for $6 \mathrm{~h}$, the cells were centrifuged and ultrasonically lysed. The antioxidant contents of GSH were determined by reacting with $5,5^{\prime}$-dithiobis-(2-nitrobenzoic acid) (DTNB), and the yellow products were evaluated by colorimetric method at $405 \mathrm{~nm}$ according to the instruction in the GSH assay kit (Nanjing Jiancheng Bioengineering Institute, china). A microtiter plate assay was used to determine the SOD activities utilizing a water-soluble tetrazolium salt (WST-1), which was used as a detector of superoxide radical generated by xanthine oxidase and hypoxanthine [66]. The SOD activity was measured with the standard SOD assay kit (Nanjing Jiancheng Bioengineering Institute, China). One unit of enzymatic activity caused 50\% inhibition of WST-1 formazan. CAT activities were determined by Goth's colorimetric method. The supernatant was incubated with $\mathrm{H}_{2} \mathrm{O}_{2}$ substrate, and the enzymatic reaction stopped by the addition of ammonium molybdate. The intensity of the yellow complex was formed by molybdate and measured at $405 \mathrm{~nm}$ [67]. One unit of activity indicated $1 \mu \mathrm{mol}$ of decomposition of $\mathrm{H}_{2} \mathrm{O}_{2}$ per second. Each experiment was repeated thrice.

\section{Observation of intracellular CdS nanoparticles}

Cells were visualized with light microscope Olympus BX51 equipped with DP70 camera to monitor the cells for any changes in the appearance after treatment with $\mathrm{Cd}$ or $\mathrm{Cd}$ and NaHS.

\section{Spectral analyses}

UV-visible absorbance spectra were recorded from 200 $\mathrm{nm}$ to $700 \mathrm{~nm}$ in the presence or absence of $\mathrm{Cd}$ or NaHS in solution using a PerkinElmer Lambda 35 spectrometer. Each spectrum represents the average of three individual scans.

\section{Extraction of total RNA}

A total of $3 \times 10^{6}$ cells were harvested from the CK, S, C, CS samples with 3 replications, immediately frozen in liquid nitrogen, and stored at $-80^{\circ} \mathrm{C}$. Total RNA was manually extracted using a TRIzol regent (Invitrogen, USA) in accordance with the manufacturer's instructions. RNA contamination and degradation were monitored on $1 \%$ agarose gels. RNA purity was checked with 
a NanoPhotometer ${ }^{\circ}$ spectrophotometer (IMPLEN, CA, USA). RNA concentration was measured with a Qubit $^{\circ}$ RNA assay kit in a Qubit ${ }^{\circ} 2.0$ fluorometer (Life Technologies, CA, USA). RNA integrity was evaluated using an RNA Nano 6000 assay kit of an Agilent Bioanalyzer 2100 system (Agilent Technologies, CA, USA).

\section{Library construction, illumina sequencing, and transcriptome assembly}

A total amount of $3 \mu \mathrm{g}$ RNA was used as input material for the RNA sample preparations. Sequencing libraries were generated using a NEBNext ${ }^{\circ}$ Ultra $^{\mathrm{mm}}$ RNA library prep kit for Illumina ${ }^{\circ}$ (NEB, USA) in accordance with the manufacturer's instructions, and index codes were added to attribute the sequences to each sample. mRNA was purified from the total RNA using poly-T oligoattached magnetic beads. Fragmentation was conducted using divalent cations at an increased temperature in a NEBNext first-strand synthesis reaction buffer $(5 x)$. First-strand cDNA was synthesized using a random hexamer primer and M-MuLV reverse transcriptase (RNase H). Second-strand cDNA was subsequently synthesized using DNA polymerase I and RNase $\mathrm{H}$. The remaining overhangs were converted into blunt ends via exonuclease/polymerase activities. After the 3' ends of the DNA fragments were adenylated, a NEBNext adaptor with a hairpin loop structure was ligated to prepare for hybridization. The library fragments were purified with an AMPure XP system (Beckman Coulter, Beverly, USA) to select the cDNA fragments with preferentially 150$200 \mathrm{bp}$ in length. Then, $3 \mu \mathrm{L}$ of USER Enzyme (NEB, USA) was used with a size-selected, adaptor-ligated cDNA initially at $37^{\circ} \mathrm{C}$ for $15 \mathrm{~min}$ and then at $95^{\circ} \mathrm{C}$ for 5 min. Then, PCR was performed with Phusion highfidelity DNA polymerase, universal PCR primers, and index $(\mathrm{X})$ primer. $\mathrm{PCR}$ products were purified (AMPure $\mathrm{XP}$ system), and library quality was assessed using the Agilent Bioanalyzer 2100 system. The index-coded samples were clustered on a cBot cluster generation system using a TruSeq PE cluster kit v3-cBot-HS (Illumina) in accordance with the manufacturer's instructions. After generating the cluster, the prepared libraries were sequenced on an Illumina Hiseq 2000 platformto generate paired-end reads. Transcriptome assembly was accomplished using Trinity [68] with min_kmer_cov set to 2 by default. All of the other parameters were set to default.

\section{Gene expression level quantification and differential expression analysis}

Gene expression levels were estimated by RSEM [69] for each sample. Clean data were mapped on the assembled transcriptome, and the read count for each gene was obtained from the mapping results. Two conditions/groups were subjected to differential expression analysis using the DESeq $\mathrm{R}$ package (1.10.1). The resulting $P$ values were adjusted using Benjamini and Hochberg's approach for controlling the FDR. Genes with an adjusted $P<0.05$ and $\mid \log 2$ (fold-change) $\mid>1$ found by DESeq were assigned as differentially expressed. The GO enrichment analysis of DEGs was implemented by the topGO $\mathrm{R}$ packages in a Kolmogorov-Smirnov (KS) test. The KEGG [70] was used to understand the functions of cells at the molecular-level (http://www.genome.jp/kegg/). KOBAS was used to evaluate the statistical enrichment of DEGs in KEGG pathways [71].

\section{qRT-PCR validation}

The total RNAs of the four different groups were extracted from the frozen cell samples with RNAiso Plus (TaKaRa, Japan). Total RNA $(2 \mu \mathrm{g})$ was reversetranscribed into first-strand cDNA using PrimeScript ${ }^{\text {tm }}$ RT reagent kit with gDNA Eraser (Takara, Japan). qRTPCR was conducted using an SYBR Green II (SYBR $^{\circ}$ Premix Ex Taq ${ }^{\mathrm{Tm}}$ Kit, Takara) in a CFX96TM real-time system (BIO-RAD, USA) through the following steps: heat for $30 \mathrm{~s}$ at $95^{\circ} \mathrm{C}$, followed by 40 cycles of $5 \mathrm{~s}$ at $95^{\circ} \mathrm{C}$ and extension for $30 \mathrm{~s}$ at $60^{\circ} \mathrm{C}$. A melting curve analysis was performed after every PCR reaction to confirm the accuracy of each amplified product. The $17 \mathrm{~S}$ rRNA gene was used as an internal control. All primers used for qRT-PCR are listed in Table S4. Amplification efficiency (E) was measured by using 4-fold serial dilutions of a positive control PCR template. The efficiency requirement was met for all the tested genes. Results were finally processed by the standard-curve method [72]. Their amplification efficiencies were greater than $90 \%$ and the correlation coefficients $\left(\mathrm{R}^{2}\right)$ were all $99 \%$ (Table S5). The relative expression levels of genes were calculated using the $2^{-\triangle \Delta C T}$ method [73]. Three independent replicates were performed for each treatment. The correlation analysis of qRT-PCR and RNA-seq were based on Pearson's correlation coefficient.

\section{Statistical analysis}

Each treatment was conducted in three replicates. Data were subjected to an analysis of variance (ANOVA). Duncan's multiple range test was used to compare significant differences at $P<0.05$ among various treatments. Different letters indicated significantly different results.

\section{Supplementary Information}

The online version contains supplementary material available at https://doi. org/10.1186/s12864-020-07337-9.

Additional file 1: Figure S1. Changes of MDA content in various $\mathrm{Cd}$ concentrations. Data are means \pm SE of three biological repeats, error 
bars indicate error standard. Means denoted by the same letter were not significantly different at $P>0.05$, and different letters indicate statistically significantly differences $(P<0.05)$ by Duncan Multiple Range Test (DMRT)

Additional file 2: Figure S2. Absorbance spectra were taken from 200 $\mathrm{nm}$ to $700 \mathrm{~nm}$ in the presence or absence of $\mathrm{Cd}$ or NaHS in solution. Each spectrum represents the average of three individual scans.

Additional file 3: Table S1. Summary for the mapped information.

Additional file 4: Figure S3. Correlation heatmap of samples. The gradient color barcode on the left presents the minimum value in pink and the maximum in blue. If one sample is highly similar to another one, the correlation between them is close to 1 .

Additional file 5: Table S2. DEGs of $\log 2 F C>8$ in CK vs. C based on RNA-seq analysis.

Additional file 6: Table S3. DEGs of $\log 2 \mathrm{FC}<-8$ in $C$ vs. CS based on RNA-seq analysis.

Additional file 7: Figure S4. GO functional analysis of DEGs. GO functional categories of DEGs in CK vs. C and C vs. CS. The ordinate coordinates represent the gene numbers and percentages in the background of all genes or DEGs. Three different classifications of the GO annotations under three basic categories are included (from left to right: biological processes, cellular component, and molecular function).

Additional file 8: Figure S5. Classification of DEGs based on KEGG analysis with respect to CK vs. C (a) and C vs. CS (b). The vertical axis represents the name of the pathway, and the horizontal axis denotes the number of genes.

Additional file 9: Figure S6. Heat-map of metabolism of xenobiotics by cytochrome P450; the colors from green to red represent the gene express values (FPKM) from low to high. The three columns represent the three experimental groups. CK represents the control group with no $\mathrm{Cd}$ or $\mathrm{NaHS}$ treatment. $\mathrm{C}$ represents the group treated by $\mathrm{Cd}$. CS represents the group with NaHS treatment under Cd stress. The genes included enriched DEGs in CK vs. C and/or C vs. CS based on KEGG analysis. Genes IDs are on the right.

Additional file 10: Figure S7. Heat-map of GSH metabolism; the colors from green to red represent the gene express values (FPKM) from low to high. The three columns represent the three experimental groups. CK represents the control group with no $\mathrm{Cd}$ or NaHStreatment. C represents the group treated by $\mathrm{Cd}$. CS represents the group with $\mathrm{NaHS}$ treatment under $\mathrm{Cd}$ stress. The genes included enriched DEGs in CK vs. C and/or C vs. CS based on KEGG analysis. Genes IDs are on the right.

Additional file 11: Figure S8. Heat-map of $A B C$ transporters; the colors from green to red represent the gene express values (FPKM) from low to high. The three columns represent the three experimental groups. CK represents the control group with no $\mathrm{Cd}$ or NaHS treatment. C represents the group treated by $\mathrm{Cd}$. CS represents the group with NaHS treatment under $\mathrm{Cd}$ stress. The genes included enriched DEGs in CK vs. $C$ and/or $C$ vs. CS based on KEGG analysis. Genes IDs are on the right.

Additional file 12: Figure S9. Cell proliferation under $70 \mu \mathrm{M}$ NaHS, 1.2 $\mathrm{mM} \mathrm{Cu}$, and $1.2 \mathrm{mM} \mathrm{Cu}+70 \mu \mathrm{M}$ NaHS treatments.

Additional file 13: Table S4. Primers used in this study.

Additional file 14: Table S5. qRT-PCR standard-curve parameters.

\footnotetext{
Abbreviations

Cd: Cadmium; $\mathrm{H}_{2} \mathrm{~S}$ : Hydrogen sulfide; NaHS: Sodium hydrosulfide; T. thermophila: Tetrahymena thermophila; ROS: Reactive oxygen species; $\mathrm{O}_{2}^{-}$: Superoxide anion; $\mathrm{OH}^{*}$ : Hydroxyl radical; $\mathrm{H}_{2} \mathrm{O}_{2}$ : Hydrogen peroxide; SOD: Superoxide dismutase; CAT: Catalase; GSH: Glutathione; GPX: Glutathione peroxidase; GST: Glutathione S-transferase; CBS: Cystathionine $\beta$-synthase; CGL: Cystathionine $\gamma$-lyase; CS: Cysteine synthase; MDA: Malondialdehyde; MTs: Metallothioneins; PCs: Phytochelatins; IC50: Half maximal inhibitory concentration; CK: Control; S: Control with $\mathrm{H}_{2} \mathrm{~S}$ treatment; C: Control under $\mathrm{Cd}$ stress; $\mathrm{CS}$ : Control with $\mathrm{H}_{2} \mathrm{~S}$ treatment under Cd stress; DEGs: Differentially expression genes; FC: Fold Change; FDR: False discovery rate; FPKM: Fragments per kilo base million; KS: KolmogorovSmirnov; GO: Gene ontology; KEGG: Kyoto Encyclopedia of Genes and
}

Genomes; qRT-PCR: Quantitative real-time polymerase chain reaction E: Amplification efficiency; $R^{2}$ : Correlation coefficient

\section{Acknowledgements}

We are grateful to anonymous reviewers for their insightful comments and remarks, which increased the quality of the manuscript. We are also grateful to members of BioMarker Technologies Co. (Beijing, China) for helpful discussion in RNA sequencing.

\section{Authors' contributions}

WW and $\mathrm{HL}$ conceived and designed the experiments. $\mathrm{HL}$ conducted experiments. $\mathrm{HL}, \mathrm{WW}, \mathrm{JX}$, and TB analyzed data. $\mathrm{HL}$ and $\mathrm{WW}$ wrote the manuscript. All authors have revised and given final approval of the version to be published.

\section{Funding}

This study was funded by National Natural Science Foundation of China (31872224, 31471999), Natural Science Foundation of Shanxi

(201901D111008, 201801D221241). The funding bodies played no role in the design of the study and collection, analysis, and interpretation of data and in writing the manuscript.

\section{Availability of data and materials}

All data supporting the conclusions of this article are provided within the article and its supplementary files. All RNA-Seq data are available in the NCBI Sequence Read Archive database under BioProject accession number PRJNA684669 (http://www.ncbi.n/m.nih.gov/bioproject/684669).

\section{Ethics approval and consent to participate}

Not applicable.

\section{Consent for publication}

Not applicable.

\section{Competing interests}

The authors declare that they have no competing interests.

\section{Author details}

${ }^{1}$ School of Life Science, Shanxi University, Taiyuan 030006, China. ${ }^{2}$ Key Laboratory of Chemical Biology and Molecular Engineering of Ministry of Education, Institute of Biotechnology, Shanxi University, Taiyuan 030006, China.

Received: 18 April 2020 Accepted: 22 December 2020

Published online: 06 January 2021

\section{References}

1. Ahmad P, Ahanger MA, Egamberdieva D, Alam P, Alyemeni MN, Ashraf M. Modification of osmolytes and antioxidant enzymes by 24-epibrassinolide in chickpea seedlings under mercury (hg) toxicity. J Plant Growth Regul. 2018; 37:309-22.

2. Gupta AD, Karthikeyan S. Individual and combined toxic effect of nickel and chromium on biochemical constituents in E. coli using FTIR spectroscopy and principle component analysis. Ecotoxicol Environ Saf. 2016;130:289-94.

3. Jan S, Alyemeni MN, Wijaya L, Alam P, Siddique KH, Ahmad P. Interactive effect of 24-epibrassinolide and silicon alleviates cadmium stress via the modulation of antioxidant defense and glyoxalase systems and macronutrient content in Pisum sativum L. seedlings. BMC Plant Biol. 2018; 18(1):146.

4. Saidi I, Ayouni M, Dhieb A, Chtourou Y, Chaïbi W, Djebali W. Oxidative damages induced by short-term exposure to cadmium in bean plants: protective role of salicylic acid. S Afr J Bot. 2013;85:32-8.

5. Khan MR, Nazir F, Asgher M, Per TS, Khan NA. Selenium and sulfur influence ethylene formation and alleviate cadmium-induced oxidative stress by improving proline and glutathione production in wheat. J Plant Physiol. 2015;173:9-18

6. Zouari M, Elloumi N, Ahmed CB, Delmail D, Rouina BB, Abdallah FB, et al. Exogenous proline enhances growth, mineral uptake, antioxidant defense, and reduces cadmium-induced oxidative damage in young date palm (Phoenix dactylifera L.). Ecol Eng. 2016;86:202-9. 
7. Gill SS, Tuteja N. Reactive oxygen species and antioxidant machinery in abiotic stress tolerance in crop plants. Plant Physiol Biochem. 2010;48(12): 909-30

8. Srikanth K, Pereira E, Duarte AC, Ahmad I. Glutathione and its dependent enzymes' modulatory responses to toxic metals and metalloids in fish-a review. Environ Sci Pollut Res Int. 2013;20(4):2133-49.

9. Kimura H. Production and physiological effects of hydrogen sulfide. Antioxid Redox Signal. 2014;20(5):783-93.

10. Zhang H, Tan ZQ, Hu LY, Wang SH, Luo JP, Jones RL. Hydrogen sulfide alleviates aluminum toxicity in germinating wheat seedlings. J Integr Plant Biol. 2010;52(6):556-67.

11. Sun J, Wang R, Zhang $X, Y u Y$, Zhao R, Li Z, et al. Hydrogen sulfide alleviates cadmium toxicity through regulations of cadmium transport across the plasma and vacuolar membranes in Populus euphratica cells. Plant Physiol Biochem. 2013;65:67-74

12. Zhang $L$, Pei $Y$, Wang $H$, Jin Z, Liu Z, Qiao Z, et al. Hydrogen sulfide alleviates cadmium-induced cell death through restraining ROS accumulation in roots of Brassica rapa L. ssp. pekinensis. Oxidative Med Cell Longev. 2015;2015:804603.

13. Mostofa MG, Rahman A, Ansary MM, Watanabe A, Fujita M, Tran LS. Hydrogen sulfide modulates cadmium-induced physiological and biochemical responses to alleviate cadmium toxicity in rice. Sci Rep. 2015;5:14078.

14. Gutiérrez JC, Amaro F, Martín-González A. From heavy metal-binders to biosensors: ciliate metallothioneins discussed. Bioessays. 2009;31(7):805-16.

15. Twagilimana L, Bohatier J, Groliere CA, Bonnemoy F, Sargos D. A new lowcost microbiotest with the protozoan Spirostomum teres: culture conditions and assessment of sensitivity of the ciliate to 14 pure chemicals. Ecotoxicol Environ Saf. 1998:41(3):231-44.

16. Gilron G, Gransden SG, Lynn DH, Broadfoot J, Scroggins R. A behavioral toxicity test using the ciliated protozoan Tetrahymena thermophila. I. Method description. Environ Toxicol Chem. 1999;18(8):1813-6.

17. Fu C, Xiong J, Miao W. Genome-wide identification and characterization of cytochrome P450 monooxygenase genes in the ciliate Tetrahymena thermophila. BMC Genomics. 2009;10:208.

18. Xiong J, Feng L, Yuan D, Fu C, Miao W. Genome-wide identification and evolution of ATP-binding cassette transporters in the ciliate Tetrahymena thermophila: a case of functional divergence in a multigene family. BMC Evol Biol. 2010;10:330.

19. Üstüntanır Dede AF, Arslanyolu M. Genome-wide analysis of the Tetrahymena thermophila glutathione S-transferase gene superfamily. Genomics. 2019;111(4):534-48.

20. Fu C, Yu T, Miao W, Shen Y. Tetrahymena: a good model organism for toxicology and ecotoxicology. Chin J Zool. 2005;40:108-13.

21. Somasundaram S, Abraham JS, Maurya S, Toteja R, Gupta R, Makhija S. Expression and molecular characterization of stress-responsive genes (hsp70 and $\mathrm{Mn}$-sod) and evaluation of antioxidant enzymes (CAT and GPX) in heavy metal exposed freshwater ciliate, Tetmemena sp. Mol Biol Rep. 2019; 46(5):4921-31

22. Martín-González A, Díaz S, Borniquel S, Gallego A, Gutiérrez JC. Cytotoxicity and bioaccumulation of heavy metals by ciliated protozoa isolated from urban wastewater treatment plants. Res Microbiol. 2006;157(2):108-18.

23. Noever DA, Matsos HC, Looger LL. Bioconvective indicators in Tetrahymena: nickel and copper protection from cadmium poisoning. J Environ Sci Health, Part A: Environ Sci Eng. 1992;27(2):403-17.

24. Dayeh VR, Lynn DH, Bols NC. Cytotoxicity of metals common in mining effluent to rainbow trout cell lines and to the ciliated protozoan, Tetrahymena thermophila. Toxicol in Vitro. 2005;19(3):399-410.

25. Ali B, Gill RA, Yang S, Gill MB, Ali S, Rafiq MT, et al. Hydrogen sulfide alleviates cadmium-induced morpho-physiological and ultrastructural changes in Brassica napus. Ecotoxicol Environ Saf. 2014;110:197-207.

26. Jia H, Wang X, Dou Y, Liu D, Si W, Fang H, et al. Hydrogen sulfide-cysteine cycle system enhances cadmium tolerance through alleviating cadmiuminduced oxidative stress and ion toxicity in Arabidopsis roots. Sci Rep. 2016; 6:39702.

27. Fu MM, Dawood M, Wang NH, Wu F. Exogenous hydrogen sulfide reduces cadmium uptake and alleviates cadmium toxicity in barley. J Plant Growth Regul. 2019;89:227-37.

28. Lv $H, X u J, B o T$, Wang $W$. Characterization of cystathionine $\beta$-synthase TtCbs1 and cysteine synthase TtCsa1 involved in cysteine biosynthesis in Tetrahymena thermophila. J Eukaryot Microbiol. 2020. https://doi.org/10. 1111/jeu.12834.
29. Yang L, Zeng J, Wang P, Zhu J. Sodium hydrosulfide alleviates cadmium toxicity by changing cadmium chemical forms and increasing the activities of antioxidant enzymes in Salix. Environ Exp Bot. 2018;156:161-9.

30. Krumov N, Oder S, Perner-Nochta I, Angelov A, Posten C. Accumulation of CdS nanoparticles by yeasts in a fed-batch bioprocess. J Biotechnol. 2007;132(4):481-6.

31. Juganson K, Mortimer M, Ivask A, Kasemets K, Kahru A. Extracellular conversion of silver ions into silver nanoparticles by protozoan Tetrahymena thermophila. Environ Sci Process Impacts. 2013;15(1):244-50.

32. Juganson K, Mortimer M, Ivask A, Pucciarelli S, Miceli C, Orupõld K, et al. Mechanisms of toxic action of silver nanoparticles in the protozoan Tetrahymena thermophila: from gene expression to phenotypic events. Environ Pollut. 2017;225:481-9.

33. Trapnell C, Pachter L, Salzberg SL. TopHat: discovering splice junctions with RNA-Seq. Bioinformatics. 2009;25(9):1105-11.

34. Chasapis CT, Andreini C, Georgiopolou AK, Stefanidou ME, Vlamis-Gardikas A. Identification of the zinc, copper and cadmium metalloproteome of the protozoon Tetrahymena thermophila by systematic bioinformatics. Arch Microbiol. 2017;199(8):1141-9.

35. Ogawa I, Nakanishi H, Mori S, Nishizawa NK. Time course analysis of gene regulation under cadmium stress in rice. Plant Soil. 2009;325:97-108.

36. Wang J, Lv Z, Lei Z, Chen Z, Lv B, Yang H, et al. Expression and functional analysis of cytochrome P450 genes in the wolf spider Pardosa pseudoannulata under cadmium stress. Ecotoxicol Environ Saf. 2019;172:19-25.

37. Armstrong RN. Glutathione S-transferases: reaction mechanism, structure, and function. Chem Res Toxicol. 1991;4(2):131-40.

38. García-Mata C, Lamattina L. Hydrogen sulphide, a novel gasotransmitter involved in guard cell signalling. New Phytol. 2010;188(4):977-84.

39. Toteja R, Makhija S, Sripoorna S, Abraham JS, Gupta R. Influence of copper and cadmium toxicity on antioxidant enzyme activity in freshwater ciliates. Indian J Exp Biol. 2017:55(10):694-701.

40. de Francisco P, Martin-Gonzalez A, Turkewitz AP, Gutierrez JC. Extreme metal adapted, knockout and knockdown strains reveal a coordinated gene expression among different Tetrahymena thermophila metallothionein isoforms. PLoS One. 2017;12(12):e0189076.

41. Zhang H, Hu LY, Hu KD, He YD, Wang SH, Luo JP. Hydrogen sulfide promotes wheat seed germination and alleviates oxidative damage against copper stress. J Integr Plant Biol. 2008;50(12):1518-29.

42. Bharwana SA, Ali S, Faroog MA, Ali B, Iqbal N, Abbas F, et al. Hydrogen sulfide ameliorates lead-induced morphological, photosynthetic, oxidative damages and biochemical changes in cotton. Environ Sci Pollut Res Int. 2014;21(1):717-31.

43. Kim JS, Kim H, Yim B, Rhee JS, Won EJ, Lee YM. Identification and molecular characterization of two cu/Zn-SODs and Mn-SOD in the marine ciliate Euplotes crassus: modulation of enzyme activity and transcripts in response to copper and cadmium. Aquat Toxicol. 2018;199:296-304.

44. Xie ZZ, Liu Y, Bian JS. Hydrogen sulfide and cellular redox homeostasis. Oxidative Med Cell Longev. 2016;2016:6043038.

45. Zhang YY, Yang J, Yin XX, Yang SP, Zhu YG. Arsenate toxicity and stress responses in the freshwater ciliate Tetrahymena pyriformis. Eur J Protistol. 2012;48(3):227-36.

46. Zhang Y, Li Z, Kholodkevich S, Sharov A, Feng Y, Ren N, et al. Cadmiuminduced oxidative stress, histopathology, and transcriptome changes in the hepatopancreas of freshwater crayfish (Procambarus clarkii). Sci Total Environ. 2019;666:944-55.

47. Díaz S, Amaro F, Rico D, Campos V, Benítez L, Martín-González A, et al, Tetrahymena metallothioneins fall into two discrete subfamilies. PLoS One. 2007;2(3):e291.

48. Viarengo A, Burlando B, Ceratto N, Panfoli I. Antioxidant role of metallothioneins: a comparative overview. Cell Mol Biol (Noisy-le-grand). 2000;46(2):407-17.

49. Rustichelli C, Visioli G, Kostecka D, Vurro E, di Toppi LS, Marmiroli N. Proteomic analysis in the lichen Physcia adscendens exposed to cadmium stress. Environ Pollut. 2008;156(3):1121-7.

50. Pocsi I, Prade RA, Penninckx MJ. Glutathione, altruistic metabolite in fungi. Adv Microb Physiol. 2004;49:1-76.

51. Zhang F, Li J, Huang J, Lin L, Wan X, Zhao J, et al. Transcriptome profiling reveals the important role of exogenous nitrogen in alleviating cadmium toxicity in poplar plants. J Plant Growth Regul. 2017:36:942-56.

52. Nair PM, Park SY, Choi J. Expression of catalase and glutathione S-transferase genes in Chironomus riparius on exposure to cadmium and nonylphenol. Comp Biochem Physiol C Toxicol Pharm. 2011;154(4):399-408. 
53. Kim SH, Jung MY, Lee YM. Effect of heavy metals on the antioxidant enzymes in the marine ciliate Euplotes crassus. Toxicol Environ Heal Sci. 2011;3(4):213-9.

54. Pastore A, Federici G, Bertini E, Piemonte F. Analysis of glutathione: implication in redox and detoxification. Clin Chim Acta. 2003;333(1):19-39.

55. Wang X, Wang C, Sheng H, Wang Y, Zeng J, Kang H, et al. Transcriptomewide identification and expression analyses of $A B C$ transporters in dwarf polish wheat under metal stresses. Biol Plant. 2017;61:293-304.

56. Bovet $L$, Feller $U$, Martinoia E. Possible involvement of plant $A B C$ transporters in cadmium detoxification: a cDNA sub-microarray approach. Environ Int. 2005;31(2):263-7.

57. Li ZS, Lu YP, Zhen RG, Szczypka M, Thiele DJ, Rea PA. A new pathway for vacuolar cadmium sequestration in Saccharomyces cerevisiae: YCF1-catalyzed transport of bis (glutathionato) cadmium. PNAS. 1997;94(1):42-7.

58. McAleer MA, Breen MA, White NL, Matthews N. pABC11 (also known as MOAT-C and MRP5), a member of the ABC family of proteins, has anion transporter activity but does not confer multidrug resistance when overexpressed in human embryonic kidney 293 cells. J Biol Chem. 1999; 274(33):23541-8

59. Long Y, Li Q, Wang Y, Cui Z. MRP proteins as potential mediators of heavy metal resistance in zebrafish cells. Comp Biochem Physiol C Toxicol Pharmacol. 2011;153(3):310-7.

60. Ning Y, Dang H, Liu G, Xiong J, Yuan D, Feng L, et al. ATP-binding cassette transporter enhances tolerance to DDT in Tetrahymena. Sci China Life Sci. 2015;58(3):297-304.

61. Einicker-Lamas M, Morales MM, Miranda K, Garcia-Abreu J, Oliveira AJ, Silva FL, et al. P-glycoprotein-like protein contributes to cadmium resistance in Euglena gracilis. J Comp Physiol B. 2003;173(7):559-64.

62. Ivanina AV, Sokolova IM. Effects of cadmium exposure on expression and activity of P-glycoprotein in eastern oysters, Crassostrea virginica Gmelin. Aquat Toxicol. 2008:88(1):19-28.

63. Xu J, Tian H, Liu X, Wang W, Liang A. Localization and functional analysis of HmgB3p, a novel protein containing high-mobility-group-box domain from Tetrahymena thermophila. Gene. 2013;526(2):87-95.

64. Gaitonde MK. A spectrophotometric method for the direct determination of cysteine in the presence of other naturally occurring amino acids. Biochem J. 1967;104(2):627-33.

65. Heath RL, Packer L. Photoperoxidation in isolated chloroplasts: I. kinetics and stoichiometry of fatty acid peroxidation. Arch Biochem Biophys. 1968;125(1): 189-98.

66. Peskin AV, Winterbourn CC. A microtiter plate assay for superoxide dismutase using a water-soluble tetrazolium salt (WST-1). Clin Chim Acta. 2000;293(1-2):157-66.

67. Ozmen B, Ozmen D, Erkin E, Güner I, Habif S, Bayındır O. Lens superoxide dismutase and catalase activities in diabetic cataract. Clin Biochem. 2002; 35(1):69-72.

68. Grabherr MG, Haas BJ, Yassour M, Levin JZ, Thompson DA, Amit I, et al. Trinity: reconstructing a full-length transcriptome without a genome from RNA-Seq data. Nat Biotechnol. 2011;29(7):644-52.

69. Li B, Dewey CN. RSEM: accurate transcript quantification from RNA-Seq data with or without a reference genome. BMC Bioinform. 2011;12:323.

70. Kanehisa M, Araki M, Goto S, Hattori M, Hirakawa M, Itoh M, et al. KEGG for linking genomes to life and the environment. Nucleic Acids Res. 2007;36: D480-4.

71. Mao X, Cai T, Olyarchuk JG, Wei L. Automated genome annotation and pathway identification using the KEGG Orthology (KO) as a controlled vocabulary. Bioinformatics. 2005;21(19):3787-93.

72. Larionov A, Krause A, Miller W. A standard curve based method for relative real time PCR data processing. BMC Bioinform. 2005;6:62.

73. Livak KJ, Schmittgen TD. Analysis of relative gene expression data using real-time quantitative PCR and the $2^{-\Delta \Delta C T}$ method. Methods. 2001;25(4): $402-8$.

\section{Publisher's Note}

Springer Nature remains neutral with regard to jurisdictional claims in published maps and institutional affiliations.

Ready to submit your research? Choose BMC and benefit from:
- fast, convenient online submission
- thorough peer review by experienced researchers in your field
- rapid publication on acceptance
- support for research data, including large and complex data types
- gold Open Access which fosters wider collaboration and increased citations
- maximum visibility for your research: over 100M website views per year
At BMC, research is always in progress.
Learn more biomedcentral.com/submissions

